\title{
M2 macrophage-secreted Slit3 intensifies sympathetic nerve function in adipose tissue and enhances thermogenesis: A long-term cold adaption way
}

\section{Yina Wang}

Key Laboratory of Metabolism and Molecular Medicine, the Ministry of Education; Department of Biochemistry and Molecular Biology of School of Basic Medical Sciences and Department of Endocrinology a

\section{Yan Tang}

Key Laboratory of Metabolism and Molecular Medicine, the Ministry of Education; Department of Biochemistry and Molecular Biology of School of Basic Medical Sciences and Department of Endocrinology a

\section{Zhihui He}

Key Laboratory of Metabolism and Molecular Medicine, the Ministry of Education; Department of Biochemistry and Molecular Biology of School of Basic Medical Sciences and Department of Endocrinology a

\section{Hong Ma}

Key Laboratory of Metabolism and Molecular Medicine, the Ministry of Education; Institutes of Biomedical Sciences, Fudan University

\section{Jiashen Li}

Key Laboratory of Metabolism and Molecular Medicine, the Ministry of Education; Department of Biochemistry and Molecular Biology of School of Basic Medical Sciences and Department of Endocrinology a

\section{Yang Liu}

Key Laboratory of Metabolism and Molecular Medicine, the Ministry of Education; Department of Biochemistry and Molecular Biology, Shanghai Medical College, Fudan University.

\section{Qiqi Yang}

Key Laboratory of Metabolism and Molecular Medicine, the Ministry of Education; Department of Biochemistry and Molecular Biology of School of Basic Medical Sciences and Department of Endocrinology a

\section{Dongning Pan}

Key Laboratory of Metabolism and Molecular Medicine, the Ministry of Education; Department of Biochemistry and Molecular Biology of School of Basic Medical Sciences and Department of Endocrinology a 


\section{Shu-Wen Qian}

Key Laboratory of Metabolism and Molecular Medicine, the Ministry of Education; Department of Biochemistry and Molecular Biology of School of Basic Medical Sciences and Department of Endocrinology a

\section{Qi-Qun Tang ( $\nabla$ qqtang@shmu.edu.cn )}

Key Laboratory of Metabolism and Molecular Medicine, the Ministry of Education; Department of Biochemistry and Molecular Biology of School of Basic Medical Sciences and Department of Endocrinology a

\section{Article}

Keywords: Macrophage, Slit3, Sympathetic neuron, Adipocyte, Thermogenesis, Beiging

Posted Date: March 10th, 2021

DOI: https://doi.org/10.21203/rs.3.rs-289849/v1

License: (c) (i) This work is licensed under a Creative Commons Attribution 4.0 International License. Read Full License

Version of Record: A version of this preprint was published at Nature Metabolism on November 15th, 2021. See the published version at https://doi.org/10.1038/s42255-021-00482-9. 


\section{M2 macrophage-secreted Slit3 intensifies sympathetic nerve}

\section{2 function in adipose tissue and enhances thermogenesis: A}

3 long-term cold adaption way

4

5 Yi-Na Wang ${ }^{1}$, Yan Tang ${ }^{1}$, Zhi-Hui $\mathrm{He}^{1}$, Hong $\mathrm{Ma}^{2}$, Jiashen $\mathrm{Li}^{1}$, Yang Liu ${ }^{1}$, Qi-Qi

6 Yang $^{1}$, Dong-Ning Pan ${ }^{1}$, Shu-Wen Qian ${ }^{1, *}$, and Qi-Qun Tang ${ }^{1, *}$

$7 \quad{ }^{1}$ Key Laboratory of Metabolism and Molecular Medicine, the Ministry of Education;

8 Department of Biochemistry and Molecular Biology of School of Basic Medical

9 Sciences and Department of Endocrinology and Metabolism of Zhongshan Hospital,

10 Fudan University, Shanghai 200032, China.

$11{ }^{2}$ Key Laboratory of Metabolism and Molecular Medicine, the Ministry of Education;

12 Institutes of Biomedical Sciences, Fudan University, Shanghai 200032, China.

*Correspondence to:

Shu-Wen Qian, E-mail: shuwenqian2013@163.com 


\section{Abstract}

Beiging of white adipose tissue (WAT) is capable of adaptive thermogenesis and dissipating energy. The beiging processes have been associated with the increase of anti-inflammatory M2 macrophages, however the function of M2 macrophage on beiging and the underlying mechanism are not fully understood. Here we identified a macrophage cytokine Slit3 by analyzing the transcriptome of M2 macrophages collected with FACS in inguinal WAT (iWAT) of mice after cold exposure. Once released from macrophages, Slit3 bound to the ROBO1 receptor on sympathetic neuron and activated tyrosine hydrolase (TH) through PKA and CaMKII signaling, and thus stimulated norepinephrine (NE) synthesis and release. NE acts on adipocytes and stimulate thermogenesis. Adoptive transfer of Slit3-overexpressing M2 macrophages to iWAT depot acquired local adipocytes with beiging phenotype and enhanced thermogenesis. In addition, mice bearing the myeloid inactivation of Slit3 were cold intolerant and gained more weight due to the lowered metabolic rate. Collectively, we demonstrate Slit3 is a macrophage cytokine and promotes beiging and thermogenesis through intensifying the sympathetic nerve function. As the expanded M2 macrophages are integral cell population in adipose tissue, the macrophage-Slit3-sympathetic neuron-adipocyte axis assures the long-term cold adaption.

Key words: Macrophage; Slit3; Sympathetic neuron; Adipocyte; Thermogenesis; Beiging 


\section{Introduction}

Adipose tissues are important organs for maintaining energy homeostasis. For energy-dealt purpose, adipose tissues have developed into different types. White adipose tissue stores energy in forms of triglycerides after nutrients load, and readily mobilizes to release fatty acids upon energy demands ${ }^{[1]}$. In contrast, brown adipose tissue dissipates energy by non-shivering thermogenesis ${ }^{[2]}$. The thermogenic function is fulfilled by mitochondrion-associated uncoupling protein 1 (UCP1), which uncouples oxidative phosphorylation to generate heat instead of $\mathrm{ATP}^{[3]}$. Classical BAT in human beings concentrates at interscapular area in infants and disappears in adulthood $^{[4]}$. Intriguingly, for the past two decades, studies have revealed a third type of adipose tissue which is aroused in white fat depots ${ }^{[5-6]}$. Such type of adipose tissue is termed as beige adipose tissue due to its brown-like activity and phenotype ${ }^{[7-8]}$. As beige adipocytes contain abundant mitochondria and are active in dissipating energy by thermogenesis, they have drawn much attention as a therapeutic target for obesity.

Beige adipose tissue is induced by responding to stimuli such as cold, exercise-induced hormones ${ }^{[9-11]}$. Upon cold exposure, sympathetic activity in adipose tissue at subcutaneous depots is effectively enhanced and norepinephrine (NE) is released from nerve terminals ${ }^{[12-13]}$. NE binds to adrenergic receptor (AR) on adipocytes and activates downstream cyclic AMP/protein kinase A (cAMP/PKA) signaling. PKA phosphorylates hormone sensitive lipase (HSL), which releases glycerol and fatty acid from lipid to fuel thermogenesis ${ }^{[14]}$. Moreover, PKA activates UCP1 transcription through phosphorylating and activating PGC1 $\alpha$, the key transcription co-activator for mitochondrial biogenesis ${ }^{[15]}$. As a result, sympathetic activation acquires adipocytes with beiging appearance.

In adipose tissue, sympathetic nerves are thought to be the main source of NE. It is very interesting that one study reported adipose tissue macrophages also released NE and promoted beiging ${ }^{[16]}$. However, the conclusion was then questioned by another study which demonstrated that deletion of tyrosine hydroxylase (TH) expression and inhibiting NE synthesis in macrophages failed to impair thermogenesis of adipose tissue $^{[17]}$. Notwithstanding whether macrophages release NE is controversial, the association between the expansion of anti-inflammatory macrophage (M2) and 
beiging has been shown in several studies ${ }^{[18-20]}$. So far, most studies focus on revealing the way M2 macrophage is activated, however how M2 macrophages promote beiging is less studied.

Adipose tissue is composed of heterogeneous cellular populations ${ }^{[21-22]}$, so the macrophage regulation on beiging may involve communication between macrophages and adipocytes, macrophages and sympathetic nerves, or even other cell types. Here, we found that M2 macrophages in subcutaneous adipose tissue of mouse were activated by cold exposure and were able to synthesize and release Slit3, a secretive protein. Slit3 activated TH activity in sympathetic nerves and stimulated NE synthesis and release, which promote thermogenesis in adipocytes and help to maintain body temperature. Considering other thermo-keeping responses (e.g. shivering and vasoconstriction) are transient, the expansion of resident M2 macrophages and Slit3 may represent a long-term pro-thermogenic way, which can help the body with cold acclimation. Therefore our study reveals a way that macrophages regulate beiging and thermogenesis, and get a new insight into the role of adipose tissue for cold adaption.

\section{Results}

\section{Slit3 is a cold induced protein secreted by M2 macrophages in iWAT}

To identify the change in the proportion of M2 macrophages in adipose tissue after cold exposure, we isolated the stromal vascular fraction (SVF) of iWAT from wildtype (WT) mice housed at $22^{\circ} \mathrm{C}$ or exposed to $4{ }^{\circ} \mathrm{C}$ for $3 \mathrm{~d}$, followed by flow cytometry (FCM) analyses. The percentage of M2 macrophages increased significantly after cold exposure (Fig. 1A). Then, we sorted M2 macrophages of the two groups by fluorescence-activated cell sorting (FACS), and the RNA of each group was extracted for transcriptome sequencing. Total 999 genes were identified to change by more than $>1.3$ fold, of which 527 were elevated in $4^{\circ} \mathrm{C}$ cold exposure group versus the $22^{\circ} \mathrm{C}$ room temperature (RT) group (Table 1). We performed enrichment analysis of KEGG pathway for prioritizing these candidates, which yielded the most significantly changed pathway of axon guidance including 19 genes (Fig. 1B). Three of the genes belong to the secretory factors, among which the expression abundance of Slit3 is the highest (Fig. 1C). Thus, we proposed Slit3 is a macrophage cytokine. 
To verify the derivation of the Slit members in adipose tissue, we first analyzed their expression in adipocytes and SVF from three adipose depots. Slit3 is highly expressed in SVF of adipose tissues, especially in iWAT (Fig. S1A). Moreover, the Slit3 mRNA levels were inducible in SVF of iWAT after cold exposure (Fig. S1B). To determine the expression of Slit3 in macrophages, M2 as well as M1 groups of macrophages in iWAT of mice housed at $22^{\circ} \mathrm{C}$ or exposed to $4^{\circ} \mathrm{C}$ for $3 \mathrm{~d}$ were sorted by FACS. The mRNA expression of Slit3 was inducible in M2 macrophages (Fig. 1C), but not in M1 macrophages (Fig. S1C). Then we isolated bone marrow derived macrophages (BMDM) and induced their polarization toward M1 and M2 macrophages with LPS or IL4 respectively. The Slit3 mRNA levels (Fig. 1E) and protein levels in conditioned medium (CM) (Fig. 1F) were both elevated in M2 macrophages but not inM1 macrophages compared to M0 macrophages, suggesting a distinguished expression pattern of Slit3 in M2 macrophages. In addition, Slit3 protein levels in cells (Fig. 1G) and CM (Fig. 1H) secreted by M2 macrophages were both induced by cold stimulation treatment at $31^{\circ} \mathrm{C}$ in vitro. These data point to a physiologic function of Slit3 in adipose tissue and are suggestive of a link between Slit3 and thermogenesis.

\section{M2 macrophages with Slit3 overexpressing increase thermogenic capacity of iWAT}

To assess whether Slit3 secreted by M2 macrophages enhances thermogenesis in vivo, we first constructed a Slit3-overexpressed adenovirus, which can significantly increase the expression of Slit3 levels in both M2 cells (Fig. 2A) and CM (Fig. 2B). M2 macrophages bearing GFP- or Slit3- overexpressing were labeled with the bioactive fluorescent dye PKH26 (Fig. S1A) and then injected into the iWAT site of WT mice by contralateral s.c. injection. (Fig. S1B). The PKH26-labeled cells were analyzed by FCM and accounted for $\sim 30 \%$ of total M2 macrophages in iWAT after one week (Fig. S1C), suggesting exogenous M2 macrophages can survive in iWAT.

The thermal image showed that the iWAT local temperature on the side injected with Slit3-overexpressed M2 macrophages was significantly higher than that on the contralateral side of the GFP control cells (Fig. 2C). At the same time, the volume of adipocytes in the side injected with Slit3-overexpressed M2 macrophages was smaller, as shown in histological sections (Fig. 2D). As anticipated, the protein levels of UCP1, 
adipose triacylglyceride lipase (ATGL) and phosphorylation of HSL was induced by Slit3 with changes in total HSL (Fig. 2E). Under the same conditions, Slit3 also increased the mRNA levels of thermogenic genes- PGC1 $\alpha, P R D M 16, P P A R \gamma$ and Cycs; lipolysis genes- $A T G L$ and $H S L$; and $\beta$-Oxidation genes- CPT1 $\beta, L C A D$, $V L C A D$ and CAD (Fig. 2F). Meanwhile, Slit3 induced a significant increase in iWAT oxygen consumption rates (Fig. 2G). To study the metabolic effects of increased Slit3, M2 macrophges overexpressing Slit3 or GFP were injected into the iWAT of WT mice bilaterally, and whole body energy expenditure was analyzed over the following 60 hours using a comprehensive laboratory animal monitoring system (CLAMS). Slit3 induced whole-body oxygen consumption (Fig. 2H-I) and elevated heat generation (Fig. 2J-K). Taken together, these results demonstrate that Slit3 secreted by M2 macrophages can promote thermogenesis in vivo.

\section{M2 macrophage-secreted Slit3 activates sympathetic activity in iWAT}

We next asked whether Slit3 can directly promote the thermogenesis of fat cells. The conditioned medium of Slit3-overexpressed M2 macrophages was collected, and added to the culture medium of adipocytes differentiated from C3H10T1/2 (Fig. 3A). However, UCP1 protein levels in C3H10T1/2 adipocytes remained unchanged after supplementing Slit3 in culture medium, so did important lipases ATGL and HSL (Fig. 3B). Similarly, the mRNA levels of thermogenic genes UCP1, PGC1 $\alpha, P R D M 16$ and PPAR $y$ were not altered (Fig. 3C). These results suggested Slit3 may indirectly promote adipocyte thermogenesis through certain other cells.

Since sympathetic activation plays a critical role in thermogenesis and lipolysis in iWAT $^{[23-24]}$, we thus sought to know whether Slit3-overexpressed M2 macrophages stimulate local sympathetic activation in iWAT. To this end, we first examined the expression of tyrosine hydroxylase $(\mathrm{TH})$, the marker of the sympathetic neurons in iWAT. Interestingly, we found a dramatic increase in both mRNA levels (Fig. 3D) and protein levels (Fig. 3E) of TH, including phospho- and total TH in iWAT of mice after Slit3-overexpressed M2 macrophages injected. We next examined the nerve density by whole-mount IHC with anti-TH antibody, and the results showed a significant increase in sympathetic nerve density upon Slit3 overexpression in M2 macrophages (Fig. 3F-G). As anticipated, we found the levels of NE, which is synthesized and 
released by sympathetic neurons, were significantly higher in iWAT (Fig. 3H), but not in serum (Fig. 3I) of mice after Slit3-overexpressed M2 macrophages injected, indicating the local activation of the sympathetic nerve by Slit3 from M2 macrophages.

\section{Thermogenic activity induced by Slit3 from M2 macrophage depends on NE/ $/$ 3-AR}

Since NE triggers the downstream signaling events via the $\beta 3$-adrenergic receptor pathway, we next examined the expression levels of adrenergic receptors. The qPCR data indicated that the mRNA levels of $\beta 3$-AR (Adrb3) were significantly increased, whereas the levels of its counteracting partner- Adra2 $\alpha$ were unchanged (Fig. 4A). To further confirm the critical role of NE/B3-AR signaling in Slit3 mediated metabolic improvements, we blocked the pathway by administrating the selective $\beta 3-\mathrm{AR}$ antagonist SR59230A to mice by intraperitoneal injection (i.p.) simultaneously with s.c. injection of M2 macrophages. We found that after injection of SR59230A, the Slit3-inducing increase in body temperature was dramatically blocked (Fig. 4B). Histologically, we found that blockade of $\beta 3$-AR by SR59230A enlarged the adipocyte size in mice with Slit3 overexpression in M2 macrophages (Fig. 4C).

We next turned to PKA signaling, a pathway known to be involved in the canonical downstream event of stimulated sympathetic tone. We found that the levels of phosphorylated PKA substrates were dramatically increased in iWAT implanted with Slit3-overexpressed M2 macrophages, which was significantly inhibited by SR59230A (Fig. 4D). Consistent with PKA activation, the increase of protein levels of UCP1 were dramatically suppressed upon SR59230A treatment (Fig. 4D). As anticipated, the lipolytic effect induced by Slit3 was impaired by blockade of $\beta 3-A R$, as shown by the downregulation of the critical lipolytic enzymes ATGL and HSL (Fig. 4D). Consequently, glycerol production induced by Slit3 in iWAT was dramatically reduced after SR59230A treatment (Fig. 4E). Furthermore, whole-body oxygen consumption (Fig. 4F-G) and heat generation (Fig. 4H-I) induced by Slit3 were significantly suppressed upon SR59230A treatment. Collectively, our results suggest that the NE/ $\beta 3$-AR pathway is necessary and sufficient for the Slit3-induced metabolic improvement. 


\section{Myeloid deletion of Slit3 impairs thermogenesis and increases body weight}

We used floxed Slit3 mice $\left(\right.$ Slit $3^{\mathrm{f} / \mathrm{f}}$ ) crossed with the lysozyme-cre strain (Lyz2 ${ }^{\text {cre }}$ ), which has been shown to target cells of myeloid lineage monocytes and primarily macrophages to generate conditional myeloid deletion of Slit3 mice referred to herein as Slit $3^{\mathrm{f} / \mathrm{f}} / \mathrm{Lyz} 2^{\text {cre }}$ mice. The percentage of M2 macrophages remained unchanged in the iWAT of Slit $3^{\mathrm{f} / \mathrm{f}} / \mathrm{Lyz} 2^{\text {cre }}$ mice compared to control mice at both $22{ }^{\circ} \mathrm{C}$ and $4{ }^{\circ} \mathrm{C}$ (Fig. S3A).

The mRNA levels (Fig. 5A) and protein levels (Fig. 5B) of Slit3 in iWAT of Slit3 ${ }^{\mathrm{f} / \mathrm{f}} / \mathrm{Lyz} 2^{\text {cre }}$ mice were both significantly reduced, although there was no significant change in serum (Fig. 5C). At the same time, the protein levels of Slit3 in gWAT (Fig. S3B) were also significantly reduced in $\mathrm{Slit} 3^{\mathrm{f} / \mathrm{f}} / \mathrm{Lyz} 2^{\text {cre }}$ mice, as a result of the presence of considerable macrophages in this adipose tissue. Meanwhile, Slit3 protein levels in BAT was slightly reduced in Slit3 ${ }^{\mathrm{f} / \mathrm{f}} / \mathrm{Lyz} 2^{\text {cre }}$ mice (Fig. S3E), most likely because there was only a small amount of macrophages in BAT. Interestingly, we found that Slit3 $3^{\mathrm{f} / \mathrm{f}} / \mathrm{Lyz} 2^{\text {cre }}$ mice were more easily to gain weight than control mice (Fig. 5D), suggesting a lower metabolic rate in Slit3 knockout mice. When exposed to $4{ }^{\circ} \mathrm{C}$ cold challenge, the ability to sustain core temperature in Slit $3^{\mathrm{f} / \mathrm{f}} / \mathrm{Lyz} 2^{\text {cre }}$ mice was significantly impaired (Fig. 5E), suggesting significant impairment of thermogenesis in mice after myeloid deletion of Slit3.

Moreover, histological examination revealed larger lipid droplets in the iWAT (Fig. 5F, top), gWAT (Fig. S3C) and BAT (Fig. S3F, top) of Slit3 ${ }^{\mathrm{f} / \mathrm{f}} / \mathrm{Lyz} 2^{\text {cre }}$ mice at both $22{ }^{\circ} \mathrm{C}$ and $4{ }^{\circ} \mathrm{C}$, and the beiging process in iWAT after Slit3 deletion was inhibited (Fig. 5F, top). We next tested sympathetic innervation in the adipose tissue, IHC results further showed reduced TH level in both iWAT (Fig. 5F, bottom) and BAT (Fig. S3F, bottom) of Slit3 $3^{\mathrm{f} / \mathrm{f}} / \mathrm{Lyz}^{\text {cre }}$ mice. Consistently, both phospho- and total TH were dramaticly reduced in the iWAT (Fig. 5G) and BAT (Fig. S3G). As anticipated, phosphorylated PKA substrates were dramatically reduced in iWAT (Fig. 5G), gWAT (Fig. S3D) and BAT (Fig. S3G) of Slit $3^{\mathrm{f} / \mathrm{f}} / \mathrm{Lyz} 2^{\text {cre }}$ mice at $22{ }^{\circ} \mathrm{C}$ and got more evident when exposed to $4{ }^{\circ} \mathrm{C}$. In addition, UCP1 levels in iWAT (Fig. 5G) but not BAT (Fig. S3G) was dramatically reduced after Slit3 deletion, and the levels of critical lipases ATGL and 
phospho-HSL were also reduced in iWAT (Fig. 5G), gWAT (Fig. S3D) and BAT (Fig. $\mathrm{S} 3 \mathrm{G})$ of Slit ${ }^{\mathrm{f} / \mathrm{f}} / \mathrm{Lyz} 2^{\text {cre }}$ mice at both $22^{\circ} \mathrm{C}$ and $4{ }^{\circ} \mathrm{C}$. As anticipated, the levels of NE were dramatically reduced in iWAT of Slit $3^{\mathrm{f} / \mathrm{f}} / \mathrm{Lyz} 2^{\text {cre }}$ mice at both $22^{\circ} \mathrm{C}$ and $4{ }^{\circ} \mathrm{C}$ (Fig. $5 \mathrm{H})$. NE levels were also reduced in serum of Slit $3^{\mathrm{f} / \mathrm{f}} / \mathrm{Lyz} 2^{\text {cre }}$ mice at $22{ }^{\circ} \mathrm{C}$, though remained unchanged at $4{ }^{\circ} \mathrm{C}$ (Fig. 5I), implying compensation of $\mathrm{NE}$ from other sources in Slit ${ }^{\mathrm{f} / \mathrm{f}} / \mathrm{Lyz} 2^{\text {cre }}$ mice. Consequently, glycerol production was dramatically reduced in the iWAT of Slit3 $3^{\mathrm{f} / \mathrm{f}} / \mathrm{Lyz} 2^{\text {cre }}$ mice when exposed to $4^{\circ} \mathrm{C}$, although there's no significant difference at $22^{\circ} \mathrm{C}$ (Fig. 5J). However, the iWAT oxygen consumption rate was significantly reduced in Slit $3^{\mathrm{f} / \mathrm{f}} / \mathrm{Lyz} 2^{\text {cre }}$ mice at both $22^{\circ} \mathrm{C}$ and $4{ }^{\circ} \mathrm{C}$ (Fig. $5 \mathrm{~K}$ ). Furthermore, whole-body oxygen consumption (Fig. 5L-M) and heat generation (Fig. $5 \mathrm{~N}-\mathrm{O})$ were both impaired in Slit $3^{\mathrm{f} / \mathrm{f}} / \mathrm{Lyz} 2^{\text {cre }}$ mice. In aggregate, these results indicate that Slit3 maintains thermogenic capacity of adipose tissue by intensifying sympathetic nerve function.

\section{Slit3 stimulates the phosphorylation of TH via PKA/CaMKII in sympathetic neuron}

Next, we sought to investigate the mechanism governing the sympathetic activation induced by Slit3. The conditioned medium of Slit3 treated PC12 sympathetic nerve cells was collected, and added to the culture medium of C3H10T1/2 adipocytes (Fig. 6A). The phosphorylated TH at Ser40 levels was significantly induced by Slit3 in PC12 cells, though total TH remained unchanged (Fig. 6B). Given that the PKA phosphorylates calcium- and calmodulin- stimulated protein kinase II (CaMPKII) at Thr286, which can then phosphorylate TH at Ser40 both in vivo and in vitro ${ }^{[25-26]}$, we set our sights on the regulation of PKA/CaMKII signaling pathway. Both the phosphorylated PKA substrates and phosphorylated CaMPKII were dramatically induced by Slit3 with no change in the level of Erk (Fig. 6C), another major protein kinase phosphorylating $\mathrm{TH}$ at Ser31 ${ }^{[26]}$. The phosphorylated PKA substrates, UCP1 and lipases in C3H10T1/2 adipocytes were both significantly induced by Slit3-treated PC12 CM (Fig. 6D).

To gain insight into whether the PKA/CaMKII signaling is critical in Slit3 induced $\mathrm{TH}$ activation and NE production in sympathetic neurons, PC12 cells were treated with Slit3 followed with treatment of H-89, a PKA-specific inhibitor, or (and) KN-93, 

significantly suppressed Slit3-stimulated phosphorylation of TH (Fig. 6E) and NE production (Fig. 6F), suggesting that PKA/CaMKII is the downstream kinases of Slit3, and plays an important role in Slit3-induced NE production in sympathetic neurons. Consequently, phosphorylated PKA substrates, UCP1 and lipases in C3H10T1/2 adipocytes induced by Slit3-treated PC12 CM were significantly suppressed by PKA/CaMKII pathway inhibition in PC12 cells (Fig. 6G). Furthermore, to study the effect of Slit3 directly secreted by M2 macrophages on PC12 sympathetic nerve cells, the conditioned medium of Slit3-overexpressed M2 macrophages was collected, and added to the culture medium of PC12 cells, of which the CM was then collected and added to the culture medium of $\mathrm{C} 3 \mathrm{H} 10 \mathrm{~T} 1 / 2$ adipocytes (Fig. S5A). We found that the phospho- TH in PC12 cells was significantly induced by Slit3 overexpressed M2 macrophages $\mathrm{CM}$ and was suppressed by KN-93 (Fig. S5B). The phosphorylated PKA substrates, UCP1 and lipases in $\mathrm{C} 3 \mathrm{H} 10 \mathrm{~T} 1 / 2$ adipocytes were both induced by CM of PC12 cells treated with Slit3-overexpressed M2 macrophages CM (Fig. S5C). Taken together, these results suggest that Slit3 stimulates the phosphorylation of TH and NE production via PKA/CaMKII signaling pathway in sympathetic neurons.

ROBO1 is the receptor for Slit3 to stimulate the phosphorylation of TH and NE production

Given that the Roundabouts (ROBOs) are canonical receptors for Slit3 ${ }^{[27]}$, we thus determined whether ROBOs are receptors in PC12 sympathetic nerve cells for Slit3. The qPCR data indicated that there was only one Robo receptor- Robol expressed in PC12 cells (Fig. 6A). Next, we knocked down ROBO1 in PC12 cells by siRNA interference, the phosphorylation of $\mathrm{TH}$ (Fig. 7B) and NE production (Fig. 7C) induced by Slit3 were both dramatically suppressed by siROBO1s treatment, as well as phosphorylated PKA substrates and phosphorylated CaMPKII (Fig. 7B). To verify cellular localization of ROBO1 in vivo, we performed IHC of ROBO1 and $\mathrm{TH}$ on the two sequential sections respectively, and found positive staining of ROBO1 showed up at TH positive sites (Fig. 7C), which indicate ROBO1 are expressed in sympathetic nerves. Collectively, our results suggest that the Slit3-ROBO1 signaling pathway is necessary for NE production in sympathetic nerve cells. 
Since there are some controversies about whether macrophages express $\mathrm{TH}^{[16-17]}$, we examined TH expression in macrophages. The result showed that both phospho- and total TH were not expressed in both M1 and M2 types of macrophages (Fig. S5A), suggesting that sympathetic neurons are a vital source of NE in adipose tissue.

\section{Inhibition of calcium-stimulated NFAT1 increases Slit3 expression in M2 macrophage}

We then explore the factors and signaling for induction of Slit3 in M2 macrophage. We found cold increased Slit3 expression, which was correlated with the increased level of phosphorylated nuclear factor of activated T Cells 2 (NFATC2 or NFAT1) shown by western blot (Fig. 8A). Since only non-phosphorylated NFAT1 can enter nuclear and act as a transcriptional factor, the correlation indicate NFAT1 is a negative regulator of Slit3 transcription. So we knockdown the NFAT1 in BMDM M2 macrophage to see whether Slit3 can be stimulated. Both qPCR and western blot showed NFAT1 were effectively down regulated, as a result, transcripts and protein of Slit3 were upregulated (Fig. 8B). As calcium influx and it effector calcineurin phosphatase accounting for NAFT1 activation, we stain BMDM M2 macrophage with calcium indicator fluo-3 AM to show the intracellular calcium concentration. The result showed the less intensive fluorescence (Fig. 8C), and thus indicating less amount of calcium in M2 macrophage after incubating at $31{ }^{\circ} \mathrm{C}$ for 1 hour. We then treated M2 cells with pry3, the blocker of transient receptor potential cation channel subfamily $\mathrm{C}$ member 3 (TRPC3), to inhibit $\mathrm{Ca}^{2+}$ influx. Pry3 treatment lead to the enhancement of both P-NFAT1 and Slit3 level showed by western blot (Fig. 8D). Collective, the data indicated a $\mathrm{Ca}^{2+}$-dependent NFAT1 pathway was involved in the cold-induced Slit3 expression.

\section{Discussion}

Here we report that when encountered with cold, percentage of M2 macrophages in iWAT was increased and more Slit3 was secreted. Slit3 activated the PKA signaling pathway in sympathetic neurons through the ROBO1 receptor, and promoted the synthesis and release of NE through the phosphorylation of TH via PKA/CaMKII pathway. NE subsequently activated the PKA signaling pathway in adipocytes through $\beta 3$ adrenergic receptor. In adipocytes, activated PKA enhanced lipolysis and 
glycerol release through phosphorylation of HSL, as well as promoted the expression of UCP1 for uncoupling respiration, so as to maintain the adaptive thermogenesis under cold environment (Fig. 9).

Adipose tissues are highly dynamic and readily change in order to adapt to the environmental alteration such as nutrients load and cold exposure ${ }^{[28-30]}$. Since adipose tissues are heterogeneous and composed of different types of cells ${ }^{[21-22]}$, the function as a metabolic organ should be fulfilled by orchestrating the different cell populations including adipocytes, immune cells, endothelial cells, neurons, fibroblasts and other undefined cells. Upon cold challenge, white adipose tissue are remolded to beiging and adipocytes gain brown-like activity with high thermogenic capacity ${ }^{[7-8]}$, which are associated with changes represented by other cells, such as a denser vasculature, higher sympathetic nerve function, and increased type2 immune cells including anti-inflammatory M2 macrophages ${ }^{[9,20,31-33]}$. Those cells communicate with each other and construct a complicated network. Studies have been carried out and clarified some parts of the network. For example, sympathetic neurons release NE to function on adipocytes, and beige adipocytes secretes cytokines to stimulated angiogenesis or regulate immune response ${ }^{[12-13,34-36]}$. In the present study, we reported M2 macrophages are able to intensify sympathetic nerve function by paracrine way relying on a secretive protein- Slit3. So Slit3 servers as the mediator for communications between macrophage and sympathetic nerves.

In the KEGG analysis of the differential expressed genes, Slit3 is included in axon guidance pathway. It was reported that Slit3 secreted from macrophages interacts with ROBO1 on schwann cells and fibroblasts in the nerve bridge to control axon guidance $^{[37]}$. Its identity and action as a macrophage derived cytokine are also indicated by another report that Slit3 from osteoclast stimulated osteoblast migration and proliferation ${ }^{[38]}$. The Slit family in mammalian consists of three members-Slit1, Slit2 and Slit3, all of which are secreted proteins with a molecular weight of approximately $150-200 \mathrm{kDa}$ and a 33 amino acid signal peptide for classical secretion. Slits are ligands for ROBOs, with the Slit receptors containing a single transmembrane domain. The Slit-ROBO signaling has been studied mainly in the 
developing nervous system ${ }^{[27,39]}$. However, in recent years the Slits functions in other tissues are gradually discovered. For example, Slit2, secreted from beige fat cells, regulates adipose tissue thermogenesis ${ }^{[40]}[40]$. These results indicates Slit family members might have the distinguished function from each other.

The signaling activated by Slit3 in sympathetic neuron is PKA/CaMKII. Considering PKA activation is also involved in adipocytes by cold-induced beiging, the signaling appears to be conserved in both sympathetic neuron and adipocytes, which might be an easier way to coordinate the different cell types. Although Slit3 activates PKA in sympathetic neurons, Slit3 has no effect on adipocytes and cannot induce UCP1 or lipases (HSL and ATGL). The absence of ROBO1 on mature adipocytes might be a cause, since the mRNA of ROBO1 cannot be detected in C3H10T1/2-derived adipocytes by qPCR.

White adipose tissue is innervated by postganglionic sympathetic neurons ${ }^{[41-42]}$. By using a viral transneuronal tract tracer, innervation of WAT has been demonstrated to originate from central nervous system ${ }^{[41]}$. After sensing cold, the sympathetic system is activated. Except for promoting thermogenesis of adipose tissue, sympathetic activation also drives muscle shivering for heat generation, as well as causes vasoconstriction for restricting heat transfer from the core to the environment ${ }^{[43]}$. These responses may represent the acute adaption to cold. However, shivering and vasoconstriction shouldn't last for too long considering they are harmful by creating metabolic burden or high blood pressure respectively. Adipose tissue macrophages through expansion may provide a sustained way to keep the body temperature, thus adapt body for cold acclimation. In our experiment, adoptive transfer of macrophages overexpressing Slit3 increased the local NE concentration, but did not obviously increase the levels in blood (Fig. 3H-I), suggesting the sympathetic activity is restricted at local site. Therefore, increase thermogenesis activation of adipose tissue through macrophage and Slit3 can be a safe and efficient way.

The ability to maintain stable body temperature is essential for mammals when encountered with cold, which requires the coordination of multiple cell types in the adipose tissue. Here, we propose that macrophage-secreted Slit3 interacts with 
ROBO1 on sympathetic neurons to intensify sympathetic nerve function and enhance thermogenesis in adipocytes to maintain body temperature. Our findings have revealed an important macrophage-secreted Slit3 function in adipose tissue metabolism. This promising function of macrophage and its secretive cytokine Slit3 could potentially be manipulated in the future for the treatment of obesity and related metabolic disorders.

\section{Methods}

\section{Animals}

All animal experiments were approved by the Fudan University Shanghai Medical College (No. 20180302-010). All mice were congenic to the C57BL6/J background and purchased from Nanjing University Model Animal Research Center. For experiments at $22^{\circ} \mathrm{C}$ (room temperature), mice were housed in cages exposed to room air. For experiments at $4^{\circ} \mathrm{C}$, mice were housed in cages inside temperature-controlled chambers set to the indicated temperature. Mice had free access to food and water in the mouse vivarium under $12 \mathrm{~h}$ light-dark cycles. Slit3-floxed and Lyz2-cre mice were purchased from Nanjing University Model Animal Research Center and bred in our vivarium to generate Slit ${ }^{\mathrm{f} / \mathrm{L}} \mathrm{Lyz}^{\mathrm{cre}}$ mice. Unless otherwise indicated, male mice at 8-9 weeks of age were used in these studies. For all in vivo studies, cohorts of greater than or equal to three mice per treatment or genotype were assembled, and experiments were repeated two to three independent times.

\section{Metabolic cage study}

For the indirect calorimetry study, we housed and monitored mice for $60 \mathrm{~h}$ in metabolic cages (Comprehensive Lab Animal Monitoring System: OXYMAX-CLAMS, Columbus Instruments) at $22^{\circ} \mathrm{C}$. Mice were housed individually and maintained on a $12 \mathrm{~h}$ light-dark cycle with lights on from 7 a.m. to 7 p.m. The first 36 hours is used for mice to acclimated to the system, then we analyzed the oxygen consumption (VO2) and heat generation during the next 24 hours. The oxygen consumption $(\mathrm{ml} / \mathrm{kg} / \mathrm{h})$ and heat generation $(\mathrm{kcal} / \mathrm{kg} / \mathrm{h})$ of each mouse were calculated according to its body weight.

\section{Cold tolerance tests}


Mice were housed within a temperature-controlled chamber (MMM Friocell, Germany) set to $4^{\circ} \mathrm{C}$, three mice per cage, with free access to food and water. Mouse rectal temperature was measured every 40 minutes using a BAT-12 microprobe thermometer with RET-3 thermocouple (Physitemp).

\section{Cell culture}

C3H10T1/2 mesenchymal stem cells were donated by Dr. M. Daniel Lane from Johns Hopkins University, and we tested for mycoplasma before experiments. Cells were cultured in Dulbecco's modified Eagle's medium (DMEM) (Gibco) supplemented with $10 \%(\mathrm{v} / \mathrm{v})$ calf serum (Sigma-Aldrich) under a low density. Two days after cell reaching confluence, the day was marked as day 0 . Preadipocytes were differentiated into adipocytes with DMEM, supplemented with 10\% fetal bovine serum (FBS) (Gibco), 0.5mM 3-isobutyl-1-methylxanthine, $1 \mu \mathrm{M}$ dexamethasone, $1 \mu \mathrm{g} / \mathrm{mL}$ insulin and $1 \mu \mathrm{M}$ rosiglitazone for two days. The cells were then cultured in fresh medium supplemented with $1 \mu \mathrm{g} / \mathrm{mL}$ insulin and $1 \mu \mathrm{M}$ rosiglitazone for another two days. From day 4 , adipocytes were cultured with DMEM containing 10\% FBS, and the medium was replaced every other day until adipocytes were used for experiments on day 6.

Rattus norvegicus pheochromocytoma PC12 cell line was purchased from American Type Culture Collection (ATCC) and was cultured in RPMI-1640 medium (Sigma-Aldrich) supplemented with 10\% heat inactivated horse serum (Hyclone) and $5 \%$ FBS. PC12 cells were plated on collagen IV (Sigma-Aldrich) -coated dishes to differentiate into sympathetic nerve cells induced by nerve growth factor (NGF) (Biosensis) for 5 days, and during this period, the medium containing new NGF was replaced every other day.

All cells were cultured and maintained at $37^{\circ} \mathrm{C}$ in a $5 \% \mathrm{CO} 2$ incubator, and the medium was supplemented with 1\% penicillin and 1\% streptomycin (Invitrogen).

\section{Isolation and culture of bone marrow derived macrophages (BMDM)}

Bone marrow cells were isolated from the femur and tibia of 6-7 weeks male C57BL/6J WT mice and differentiated to mature macrophages for 7 days as described $^{[44]}$. Briefly, cells were maintained at DMEM with $10 \%$ FBS, containing 10 
ng/ml M-CSF (Peprotech). On day 7, 100 ng/ml LPS (Peprotech) or $10 \mathrm{ng} / \mathrm{ml} \mathrm{IL4}$ (Peprotech) were added for M1 or M2 polarization respectively. The polarization were considered complete after 24 hours of maintenance.

\section{M2 macrophages transfer assay}

BMDMs were isolated and cultured according to standard procedure and polarized into M2 macrophages by IL4 $(10 \mathrm{ng} / \mathrm{ml})$ followed with GFP- or Slit3- adenovirus treatment, and then enzymatically dissociated and collected. The same number $\left(3 \mathrm{X} 10^{6}\right)$ of GFP- adenovirus or Slit3 overexpressed- adenovirus treated M2 macrophages were injected into subcutaneous site adjacent to the inguinal fat every two days for a total of three times. The mice were then carried on metabolic cage study at day 7 after the third M2 macrophages transfer. At day 9 , the mice were fasted for 5h and sacrificed, tissues and sera were collected for further analyses.

\section{Treatment of SR59230A}

For the treatment with the selective $\beta 3$-adrenoceptor antagonist SR59230A, mice were i.p. injected with $1 \mathrm{mg} / \mathrm{kg}$ body weight of dissolved SR59230A or with $1 \%$ dimethyl sulfoxide (DMSO)-phosphate-buffered saline (PBS) placebo every day along with the M2 macrophages transfer. SR59230A compound (Sigma-Aldrich) was dissolved in 1\% DMSO-PBS buffer.

\section{Mature adipocytes and SVF isolation}

Freshly isolated adipose tissue was finely minced with scissors and incubated in digest buffer containing $0.075 \%$ collagenase Type VIII (Sigma-Aldrich) for 30-40 min at $37^{\circ} \mathrm{C}$ with shaking and occasional vortexing. The digested samples were filtered through a $100 \mu \mathrm{m}$ strainer, then centrifuged at $1700 \mathrm{rpm}$ for 5 minutes. The adipocytes in the upper layer were removed to a new tube and washed with PBS, then centrifuged at $1700 \mathrm{rpm}$ for 5 minutes for collection. The stromal vascular fraction (SVF) in the bottom layer were resuspend with ammonium chloride lysis buffer (1.5M NH4Cl, 100nM KHCO3, 10nM Na2EDTA), then centrifuged at $1700 \mathrm{rpm}$ for 5 minutes for collection.

\section{Flow cytometric analysis of SVF of iWAT}


Fresh SVF isolated from iWAT were fixed with $10 \%$ calf serum (CS) in PBS for 30

505

506

507

508

509

510

511

512

513

514

515

516

517

518

519

520

521

522

523

524

525

526

527

528

529

530

531

532

533

534

535

536

minutes. Cells were washed with PBS and incubated with fluorochrome-conjugated antibodies against surface antigens in 2\% CS- PBS. Stained cells were analyzed with a BD FACSVerse flow cytometer. The data was analyzed with FlowJo (FlowJo, LLC). Gates were constructed to identify target populations based on surface marker staining. $\mathrm{M} 2$ macrophages were identified as $\mathrm{CD} 45^{+} \mathrm{F} 4 / 80^{+} \mathrm{CD} 206^{+}$, and $\mathrm{M} 1$ macrophages were identified as $\mathrm{CD} 45^{+} \mathrm{F} 4 / 80^{+} \mathrm{CD} 11 \mathrm{c}^{+}$. The Percp-CD45 was purchased from BD Biosciences, FITC-F4/80, PE-CD206 and APC-CD11c were purchased from Biolegend.

\section{RNA extraction and quantitative real-time PCR}

RNA was extracted from cultured cells or frozen tissue samples using TRIzol (Invitrogen). Normalized RNA was reversed transcribed using RevertAid First Strand cDNA Synthesis kit (Thermo Fisher) and cDNA was analysed by qRT-PCR through the 7500 Fast Real-Time PCR System (Applied Biosystems). Relative mRNA levels were calculated using the comparative CT method and normalized to $18 \mathrm{~s}$ rRNA mRNA. The average of the control group was set as one, and all the results as the relative mRNA expression was represented. All primers used are listed with their sequences in Supplemental Table S1.

\section{Western blot}

For western blotting, homogenized tissues, whole cell lysates or concentrated serum free conditioned medium were lysed in $2 \%$ sodium dodecyl sulfate (SDS) buffer containing protease inhibitor cocktail (Roche) and phosphatase inhibitor cocktail

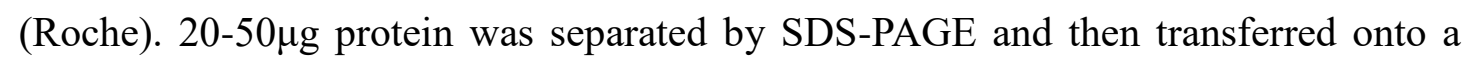
polyvinylidene fluoride (PVDF, $0.22 \mu \mathrm{m}$ ) transfer membrane using the wet transfer method. Membranes were blocked with 5\% fat free milk in TBST (Tris buffered saline plus $0.1 \%$ Tween-20) for one hour at room temperature. Primary antibodies were diluted (1:1000) in 3\% bovine serum albumin (BSA) (in TBST) and the membranes were incubated in primary antibodies overnight at $4{ }^{\circ} \mathrm{C}$. The next day, the membranes were washed in TBST ( $3 \times 10$ minutes) and then incubated with HRP conjugated secondary antibody (1:10000 in 3\% BSA TBST) for one hour at room temperature. After TBST washes (4x10 minutes), Pierce ECL western blotting 
substrate was added onto the membrane and incubated for two minutes to develop the chemiluminescent signal.

Antibody for Slit3 and ROBO1 were from R\&D Systems. Antibody for total TH was from EMD Milipore. Antibody for $\beta$-actin and UCP1 were from abcam. Antibody for phospho-TH, phospho-PKA Substrate, phospho-HSL, total HSL, phospho-CaMKII, total CaMKII, phospho-ERK, total ERK, aP2 and ATGL were from Cell Signaling Technology.

\section{Histology}

Freshly isolated adipose tissue was fixed in $4 \%$ paraformaldehyde for 24 hours at room temperature. Tissues were embedded in paraffin, sectioned at $5 \mu \mathrm{m}$ thickness, deparaffinized and rehydrated through graded concentrations of ethanol in water. Sections were then stained with hematoxylin and eosin (H\&E) (Sigma-Aldrich). For immunohistochemistry (IHC) staining, sections were probed with primary antibody against TH (Abcam), followed by biotinylated secondary antibody. Binding of second antibodies was visualized by using diaminobenzidine (DAB) chromogen A (Thermo Fisher).

\section{Measurement of NE levels}

The NE levels in serum and conditioned medium were detected and quantified by an enzyme-linked immunosorbent assay (ELISA) kit (Labor Diagnostika Nord GmbH \& Co. KG) according to the manufacturer's instructions. To examine the NE levels in adipose tissue, iWAT was homogenized in chilled homogenization buffer $(1 \mathrm{~N} \mathrm{HCl}$, $0.25 \mathrm{M}$ EDTA, and $1 \mathrm{M} \mathrm{Na}_{2} \mathrm{~S}_{2} \mathrm{O}_{5}$ in PBS) with proteinase inhibitors, and the supernatants were collected by centrifugation at $4{ }^{\circ} \mathrm{C}$ for $\mathrm{NE}$ analysis after removal of the fat cake at the top. The NE levels were normalized to the protein concentration of total tissue.

\section{Measurement of glycerol production}

The glycerol levels in serum were detected and quantified by Glycerol Assay Kit (Applygen) according to the manufacturer's instructions. To examine the glycerol production in adipose tissue, iWAT was homogenized in chilled PBS with proteinase 
inhibitors, and the supernatants were collected by centrifugation at $4^{\circ} \mathrm{C}$ for glycerol levels after removal of the fat cake at the top. The glycerol levels were normalized to the protein concentration of total tissue.

\section{Construction and infection with cells of adenoviral expression vectors}

Recombinant adenovirus for Slit3 overexpression (Ad-Slit3) was constructed using the ViraPower Adenoviral Expression System (Invitrogen) according to the manufacturer's instructions. The GFP recombinant adenovirus (Ad-GFP) was used as a negative control. The M2 macrophages in $3.5 \mathrm{~cm}$ dishes were infected with $20 \mu 1$ crude virus, supplied with $8 \mu \mathrm{g} / \mathrm{mL}$ polybrene (Sigma) for enhancing adenovirus infection efficiency. The medium was replaced $24 \mathrm{~h}$ after, the cells were cultured for another two days and then collected for analysis.

\section{RNA-seq}

M2 macrophages in iWAT were sorted by FACS with a Beckman moflo Astrios EQ (Beckman) flow cytometer, the RNA was then extracted for RNA-seq. For construction of RNA-seq libraries, a TruSeq Stranded mRNA Library Prep Kit (Illumina) was used according to the manufacturer's instructions. $1 \mu \mathrm{g}$ of total RNA was used as the starting material. PolyA-containing RNA was purified and fragmented, followed by first and second strand cDNA synthesis, adapter ligation, and PCR amplification (15 cycles). A library size of 200-300 bp was verified by agarose gel electrophoresis and library concentration was measured with a Qubit dsDNA High Sensitivity Assay Kit and a Qubit 2.0 fluorimeter (Thermo Fisher Scientific). Libraries were pooled (up to 24 per run), denatured with $\mathrm{NaOH}$, diluted to $1.8 \mathrm{pM}$, and sequenced on a NextSeq 500 Sequencing System (Illumina) with a NextSeq 500/550 High Output v2 kit (75 cycles, Illumina) in single-read mode.

\section{Whole body thermal imaging}

Mice were anesthetized with isoflurane and fixed to foam board, the whole body temperature was recorded with an E60 FLIR infrared camera.

\section{Oxygen consumption rate of iWAT}

We used an OxygenMeter (Strathkelvin Instruments) with a Mitocell (MT200) mixing 
chamber to investage the oxygen consumption rate (OCR) of iWAT. We cut off about 40-60mg of iWAT into small pieces and then subjected them to test OCR. We recorded the oxygen concentration for 2 minutes and used 782 Oxygen System version 4.0 software to calculate the OCR, results were normalized to the tissue weight.

\section{Statistical analysis}

All data are represented in the figures as mean values \pm SEM. The statistical significance was analyzed using the student's $t$ test for comparing two groups and ANOVA for multiple groups. P values are indicated with $* \mathrm{p}<0.05$, ** $\mathrm{p}<0.01$, $* * * \mathrm{p}<0.001$ and $* * * * \mathrm{p}<0.0001$ on graphs. Where graphs are not labeled with an asterisk, any differences between the test groups and the control groups were non-significant.

\section{Data availability statement}

All data pertaining to the findings of this study are available upon request from the corresponding authors:
Dr. Shu-Wen Qian, E-mail: shuwenqian2013@163.com

Dr. Qi-Qun Tang, E-mail: qqtang@shmu.edu.cn

\section{Author contributions}

QQT, SWQ and YNW conceived and designed the experiments; YNW and SWQ wrote the manuscript; SWQ and QQT administrated project; SWQ and QQT acquired funding; YNW, SWQ, YT, ZHH, HM, YL, QQY and JSL performed experiments; DNP, YNW and SWQ reviewed and edited writing.

\section{Funding support}

This work was supported by National Key R\&D Program of Ministry of Science and Technology of China (2018YFA0800401) to Q.-Q.T., National Natural Science Foundation (NSFC) Grants 31670787 to S.-W.Q., 81730021 to Q.-Q.T. and 81970754 to Y.T..

\section{Conflict of Interest Statement}


The authors declare that the research was conducted in the absence of any commercial or financial relationships that could be construed as a potential conflict of interest.

\section{References}

[1] Abdullahi A, Jeschke MG. Taming the flames: Targeting white adipose tissue browning in hypermetabolic conditions. Endocr Rev, 2017, 38(6): 538-549.

[2] Cannon B, Nedergaard J. Brown adipose tissue: function and physiological significance. Physiol Rev, 2004, 84(1): 277-359.

[3] Aquila H, Link TA, Klingenberg M. The uncoupling protein from brown fat mitochondria is related to the mitochondrial ADP/ATP carrier. Analysis of sequence homologies and of folding of the protein in the membrane. 1985, EMBO J, 4(9): 2369-2376.

[4] Enerbäck S. Human brown adipose tissue. Cell Metab. 2010, 11(4): 248-52.

[5] Xue B, Rim JS, Hogan JC, et al. Genetic variability affects the development of brown adipocytes in white fat but not in interscapular brown fat. J Lipid Res, 2007, 48(1): 41-51.

[6] Petrovic N, Walden TB, Shabalina IG, et al. Chronic peroxisome proliferator-activated receptor $\gamma(\operatorname{PPAR} \gamma)$ activation of epididymally derived white adipocyte cultures reveals a population of thermogenically competent, UCP1-containing adipocytes molecularly distinct from classic brown adipocytes. J Biol Chem, 2010, 285(10): 7153-64.

[7] $\mathrm{Wu} \mathrm{J}$, Boström P, Sparks LM, et al. Beige adipocytes are a distinct type of thermogenic fat cell in mouse and human. Cell, 2012, 150(2): 366-76.

[8] Wang W, Seale P. Control of brown and beige fat development. Nat Rev Mol Cell Biol, 2016, 17(11): 691-702.

[9] Jiang H, Ding X, Cao Y, et al. Dense intra-adipose sympathetic arborizations are essential for cold-induced beiging of mouse white adipose tissue. Cell Metab, 2017, 26(4): 686-92.

[10] Hsu JW, Nien CY, Yeh SC, et al. Phthalate exposure causes browning-like effects on adipocytes in vitro and in vivo. Food Chem Toxicol, 2020, 142: 111487.

[11] Picoli CC, Gilio GR, Henriques FDS, et al. Resistance exercise training induces subcutaneous and visceral adipose tissue browning in Swiss mice. J Appl Physiol, 2020, 129(1): 66-74.

[12] Zaror-Behrens G, Himms-Hagen J. Cold-stimulated sympathetic activity in 
678

679

680

681

682

683

684

685

686

687

688

689

690

691

692

693

694

695

696

697

698

699

700

701

702

brown adipose tissue of obese (Ob/Ob) mice. Am J Physiol, 1983, 244(4): E361-366.

[13] Sigurdson SL, Himms-Hagen J. Control of norepinephrine turnover in brown adipose tissue of syrian hamsters. Am J Physiol, 1988, 254(6): R960-968.

[14] Hucking K, Hamilton-Wessler M, Ellmerer M, et al. Burst-like control of lipolysis by the sympathetic nervous system in vivo. J Clin Invest, 2003, 111(2): 257-264.

[15] Chouchani ET, Kazak L, Spiegelman BM. New advances in adaptive thermogenesis: UCP1 and beyond. Cell Metab, 2019, 29(1): 27-37.

[16] Nguyen KD, Qiu Y, Cui X, et al. Alternatively activated macrophages produce catecholamines to sustain adaptive thermogenesis. Nature, 2011, 480(7375): 104-108.

[17] Fischer K, Ruiz HH, Jhun K, et al. Alternatively activated macrophages do not synthesize catecholamines or contribute to adipose tissue adaptive thermogenesis. Nat Med, 2017, 23(5): 623-30.

[18] Molofsky AB, Nussbaum JC, Liang HE, et al. Innate lymphoid type 2 cells sustain visceral adipose tissue eosinophils and alternatively activated macrophages. J Exp Med, 2013, 210(3): 535-549.

[19] Rao RR, Long JZ, White JP, et al. Meteorin-like is a hormone that regulates immune-adipose interactions to increase beige fat thermogenesis. Cell, 2014, 157(6): 1279-1291.

[20] Brestoff JR, Kim BS, Saenz SA, et al. Group 2 innate lymphoid cells promote beiging of white adipose tissue and limit obesity. Nature, 2015, 519(7542): 242-246.

[21] Esteve Ràfols M. Adipose tissue: cell heterogeneity and functional diversity. Endocrinol Nutr. 2014, 61(2): 100-112.

[22] Weinstock A, Moura Silva H, Moore KJ, et al. Leukocyte heterogeneity in adipose tissue, including in Obesity. Circ Res, 2020, 126(11): 1590-1612.

[23] Zeng W, Pirzgalska RM, Pereira MM, et al. Sympathetic neuro-adipose connections mediate leptin-driven lipolysis. Cell, 2015, 163 (1): 84 -94.

[24] Peirce V, Carobbio S and Vidal-Puig A. The different shades of fat. Nature, 2014, 510(7503): 76-83.

[25] Vulliet PR, Woodgett JR, and Cohen P. Phosphorylation of tyrosine hydroxylase 
by calmodulin-dependent multiprotein kinase. 1984, J Biol Chem, 259(22): 13680-13683.

[26] Dunkley PR, Dickson PW. Tyrosine hydroxylase phosphorylation in vivo. J Neurochem, 2019,149(6): 706-728.

[27] Brose K, Bland KS, Wang KH, et al. Slit proteins bind Robo receptors and have an Evolutionarily conserved role in repulsive axon guidance. Cell, 1999, 96(6): 795-806.

[28] Van Marken Lichtenbelt WD, Vanhommerig JW, SmuldersNM, Drossaerts JM, et al. Cold-actived brown adipose tissue in healthy men. N Engl J Med, 2009, 360(15): 1500-1508.

[29] Nedegaard J, Bengtsson T, Cannon B. Unexpected evidence foractive brown adipose tissue in adult humans. Am J Physiol Endocrinol Metab, 2007, 293(2): E444-452..

[30] Pittenger MF, Mackay AM, Beck SC, et al. Multilineage potential of adult human mesenchymalstem cells. Science, 1999, 284:143-147.

[31] Qian SW, Wu MY, Wang YN, et al. BMP4 facilitates beige fat biogenesis via regulating adipose tissue macrophages. J Mol Cell Biol, 2019, 11(1): 14-25.

[32] Kang K, Reilly SM, Karabacak V, et al. Adipocyte-derived Th2 cytokines and myeloid PPARdelta regulate macrophage polarization and insulin sensitivity. Cell Metab, 2008, 7(6):485-495.

[33] Odegaard JI, Ricardo-Gonzalez RR, Red Eagle A, et al. Alternative M2 activation of Kupffer cells by PPARdelta ameliorates obesity-induced insulin resistance.Cell Metab, 2008, 7(6): 496-507.

[34] Hui X, Gu P, Zhang J, et al. Adiponectin enhances cold-induced browning of subcutaneous adipose tissue via promoting M2 macrophage proliferation. Cell Metab, 2015, 22(2): 279-290.

[35] Mauer J, Chaurasia B, Goldau J, et al. Signaling by IL-6 promotes alternative activation of macrophages to limit endotoxemia and obesity-associated resistance to insulin. Nat. Immunol, 2014, 15(5): 423-430.

[36] Rao RR, Long JZ, White JP, et al. Meteorin-like is a hormone that regulates immune-adipose interactions to increase beige fat thermogenesis. 2014, Cell, 157(6): 1279-1291.

7] Dun XP, Carr L, Woodley PK, et al. Macrophage-derived Slit3 controls cell 
migration and axon pathfinding in the peripheral nerve bridge. Cell Rep, 2019, 26(6): 1458-1472.

[38] Kim BJ, Lee YS, Lee SY, et al. Osteoclast-secreted SLIT3 coordinates bone resorption and formation. J Clin Invest, 2018, 128(4):1429-1441.

[39] Li HS, Chen JH, Wu W, et al. Vertebrate Slit, a secreted ligand for the transmembrane protein roundabout is a repellent for olfactory bulb axons. Cell, 1999, 96(6): 807-818.

743 [40] Svensson KJ, Long JZ, Jedrychowski MP, et al. A secreted Slit2 fragment regulates adipose tissue thermogenesis and metabolic function. Cell Metab, 2016, 23(3): 454-466.

[41] Bamshad M, Aoki VT, Adkison MG, et al. Central nervous system origins of the sympathetic nervous system outflow to white adipose tissue. Am J Physiol, 1998, 275(1): R291-299.

[42] Boulant JA. Neuronal basis of Hammel's model for set-point thermoregulation. J Appl Physiol, 2006, 100(4): 1347-1354.

[43] Castellani JW, Young AJ. Human physiological responses to cold exposure: Acute responses and acclimatization to prolonged exposure. Auton Neurosci, 2016, 196: 63-74.

[44] Ying W, Cheruku PS, Bazer FW, et al. Investigation of macrophage polarization using bone marrow derived macrophages. J Vis Exp, 2013, 23(76): 50323. 
Figure 1

A

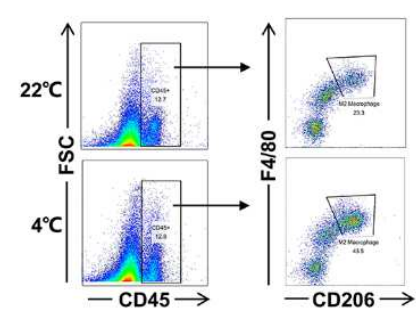

C

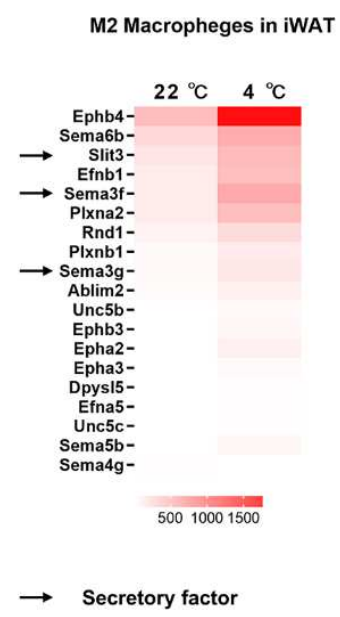

D

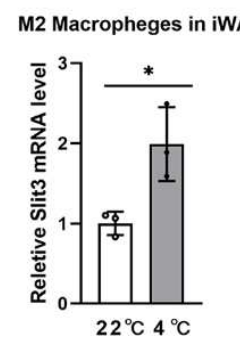

G

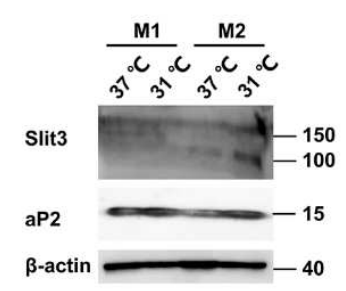

$E$
M2 Macropheges in iWAT
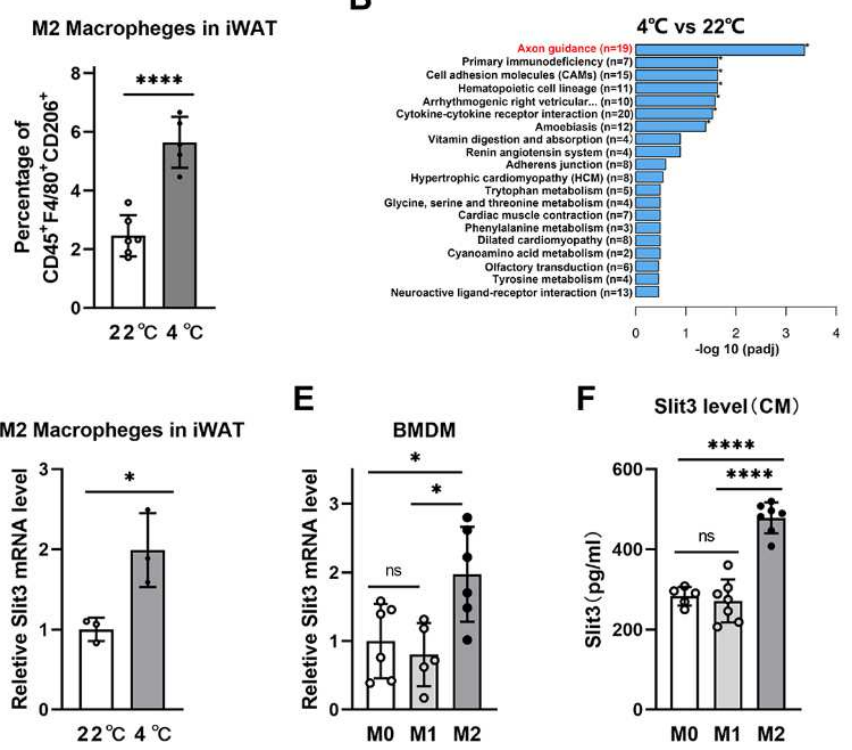

F Slit3 level(CM)

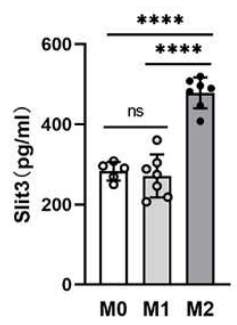

H

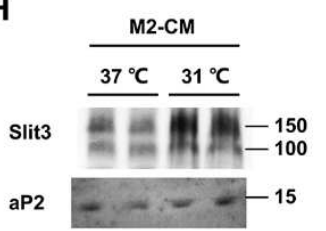
macrophages in iWAT

A. Flow cytometry analysis for M2 macrophages $\left(\mathrm{CD} 45^{+} \mathrm{F} 4 / 80^{+} \mathrm{CD} 206^{+}\right)$in iWAT from mice housed at $22^{\circ} \mathrm{C}$ or exposed to $4^{\circ} \mathrm{C}$ for $3 \mathrm{~d}(\mathrm{n}=6 / 5)$.

B-C. Enrichment analysis of KEGG pathway(B) and heat map (C) showing relative mRNA levels in $\mathrm{M} 2$ macrophages in iWAT from mice housed at $22^{\circ} \mathrm{C}$ or exposed to $4^{\circ} \mathrm{C}$ for $3 \mathrm{~d}(\mathrm{n}=1$ per group). The heat map based on fragments per kilobase of exon model per million mapped fragments (FPKM).

D. Gene expression of Slit 3 in M2 macrophages in iWAT from mice housed at $22^{\circ} \mathrm{C}$ or exposed to $4^{\circ} \mathrm{C}$ for $3 \mathrm{~d}$ ( $\mathrm{n}=3$ per group). M2 macrophages were collected by FACS on total SVF pooled from 30 mice in each group, the experiment was repeated for 3 times.

E. Gene expression of Slit3 in M0, M1 and M2 Macrophages (n=5-6 per group).

F. Slit3 levels in conditioned medium (CM) from M0, M1 and M2 macrophages was determined by ELISA analyze ( $\mathrm{n}=5-7$ per group).

G. Western blotting against Slit3, aP2 in M1 and M2 macrophages.

$\mathrm{H}$. Western blotting against Slit3 from concentrated M2 macrophages CM.

Data are presented as mean \pm SEM. Student's t test was used for comparisons. ${ }^{*} \mathrm{p}<0.05,{ }^{* *} \mathrm{p}<$ 
A

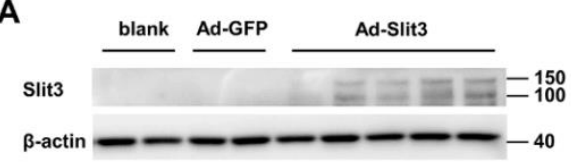

D

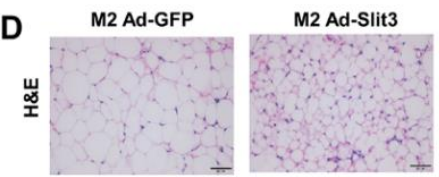

E

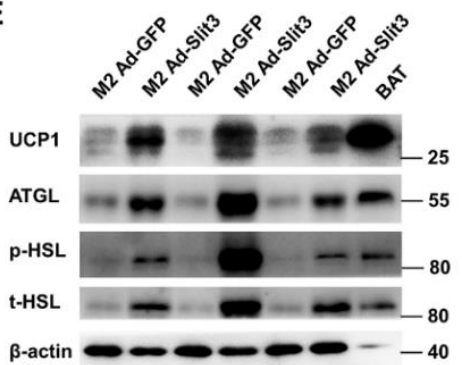

B

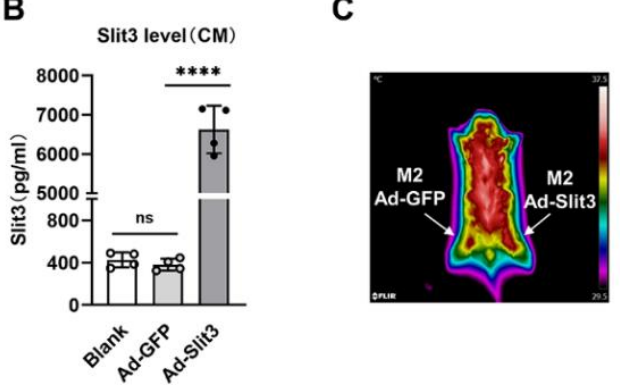

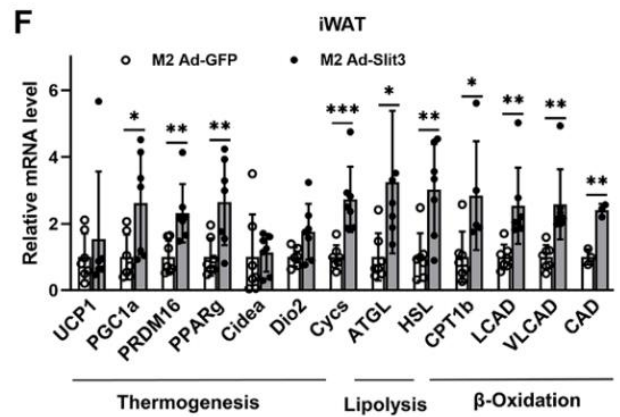
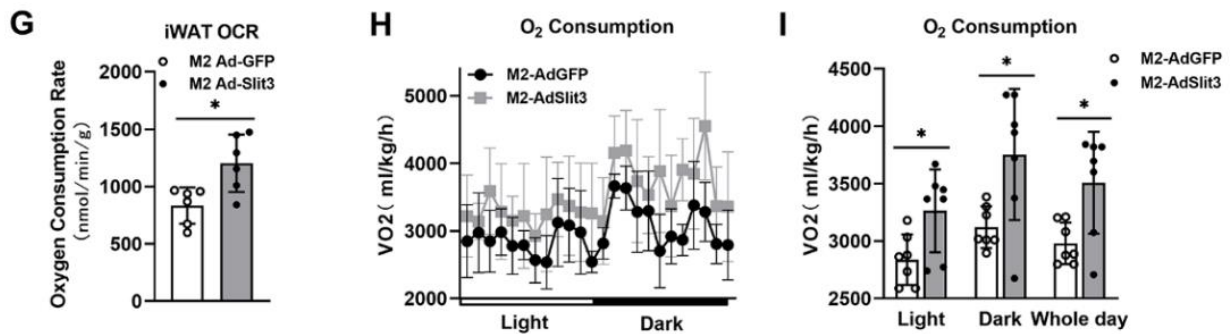

J

K
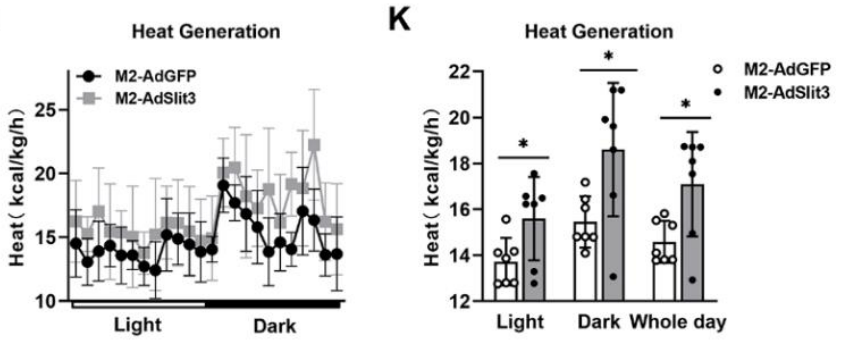

Figure 2: M2 macrophages with Slit3 overexpressed increases thermogenic capacity of iWAT A. Western blotting against Slit3 in untreated or Slit3 overexpressed adenovirus-infected M2 macrophages.

B. Slit3 levels in CM from untreated or Slit3 overexpressed adenovirus-infected M2 macrophages was determined by ELISA analyze ( $\mathrm{n}=4$ per group).

C. The whole body temperature of mice after M2 macrophages injected was analyzed by a thermal imaging system.

D. H\&E staining of iWAT collected from mice after M2 macrophages injected.

E. Western blot analysis of UCP1, phospho- and total HSL and ATGL in iWAT of mice after M2 macrophages injected. macrophages injected ( $\mathrm{n}=5-8$ per group). G. Oxygen consumption rate (OCR) of iWAT isolated from mice after M2 macrophages injected was measured and shown ( $\mathrm{n}=6$ per group). $0.01, * * * \mathrm{p}<0.001, * * * * \mathrm{p}<0.0001$. 


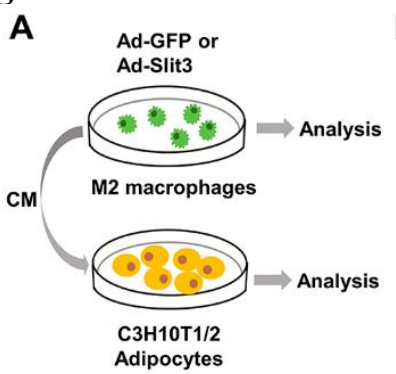

B
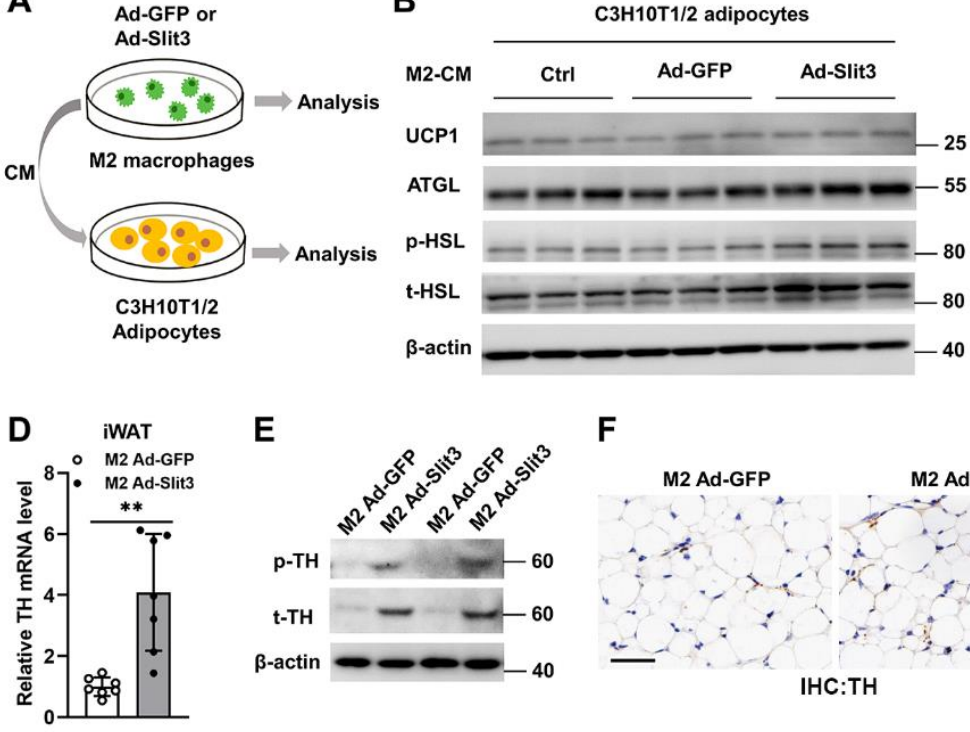

E

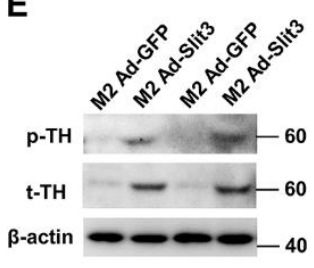

F

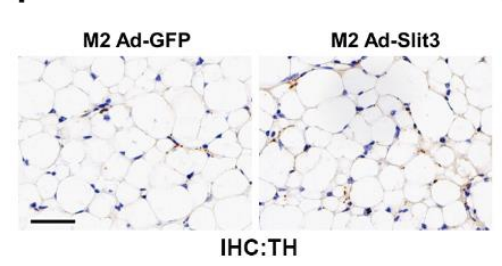

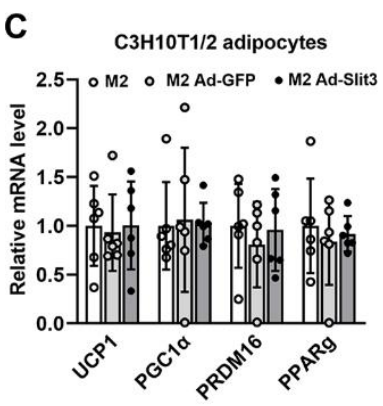

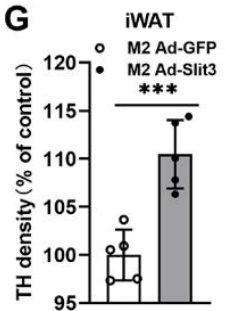

806
H NE Level(iWAT)

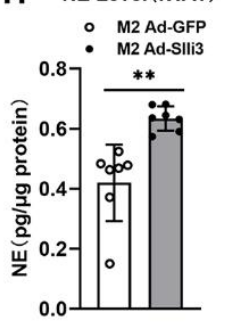

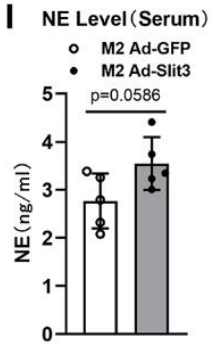

Figure 3: M2 macrophage-secreted Slit3 activates TH activity in sympathetic nerves

A. Experimental approach to evalute the effect of Slit3 overexpressed M2 macrophages on C3H10T1/2 adipocytes.

B. Western blot analysis for UCP1, ATGL and phospho- and total HSL in C3H10T1/2 adipocytes upon 24h-treatment with conditioned medium from M2 macrophages.

C. Normalized gene expression in C3H10T1/2 adipocytes upon 24h-treatment with conditioned medium from $\mathrm{M} 2$ macrophages ( $\mathrm{n}=6$ per group).

D. qPCR analysis of TH expression in iWAT of mice after M2 macrophages injected ( $n=7$ per group).

E. Western blot analysis of phospho- and total TH in iWAT of mice after M2 macrophages injected.

F. IHC staining with anti-TH antibody in iWAT of mice after M2 macrophages injected. Scale bar: $20 \mu \mathrm{m}$.

G. Density analysis and statistics of the results shown in panel $\mathrm{E}$ ( $\mathrm{n}=5$ per group).

H. NE levels in iWAT of mice after M2 macrophages injected. Results were normalized to the total protein levels ( $\mathrm{n}=7$ per group).

I. NE levels in serum of mice after M2 macrophages injected ( $\mathrm{n}=5$ per group).

Data are presented as mean \pm SEM. Student's t test was used for comparisons. ${ }^{*} \mathrm{p}<0.05,{ }^{* *} \mathrm{p}<$ $0.01,{ }^{* * *} \mathrm{p}<0.001,{ }^{* * * *} \mathrm{p}<0.0001$. 

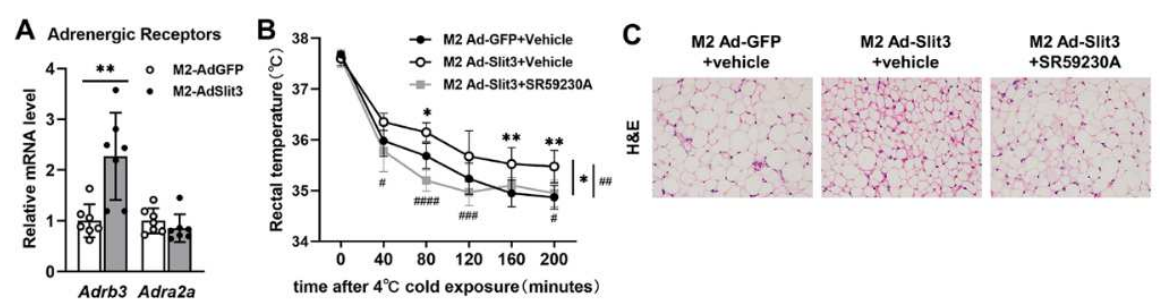

D
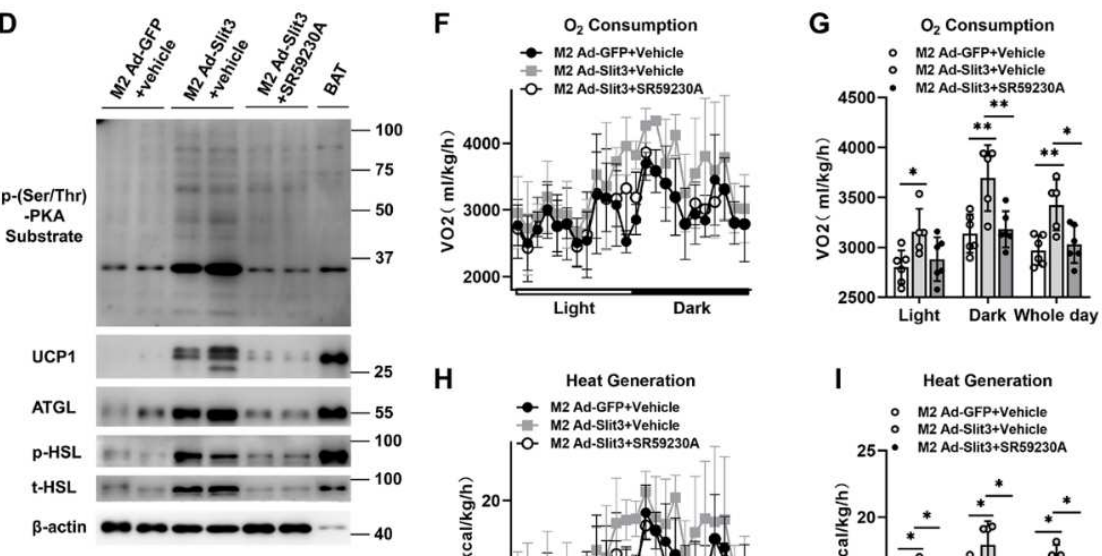

E Glycerol Level( IWAT)
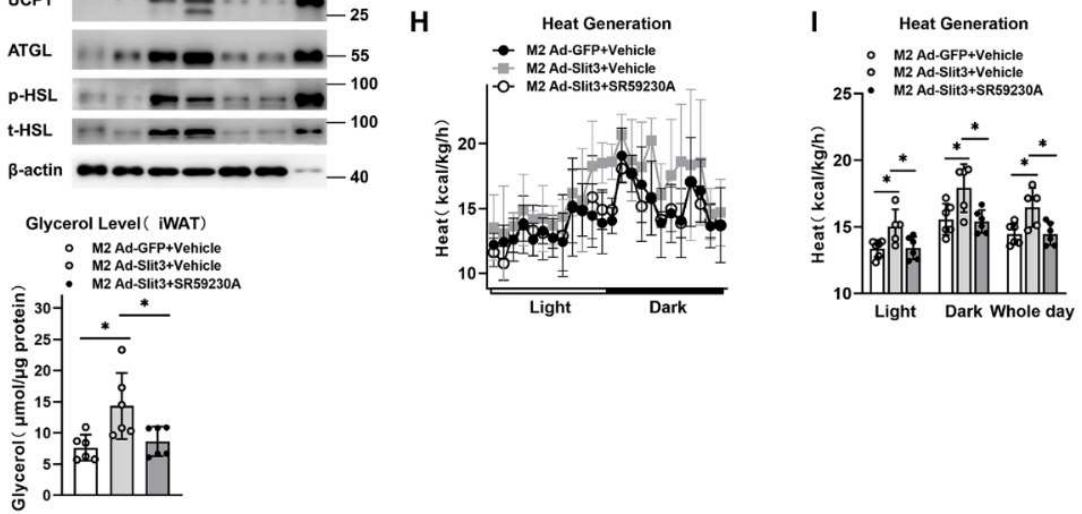

Figure 4: Thermogenic activity induced by Slit3 from M2 macrophage depends on

A. qPCR analysis of adrenergic receptor genes, namely, $A d r b 3$ and Adra $2 a$, in iWAT of mice after M2 macrophages injected ( $\mathrm{n}=7$ per group).

B. Rectal temperature measurements of mice after M2 macrophages injected, with or without SR59230A treatment for 7 days, which bred at $22{ }^{\circ} \mathrm{C}$ and subjected to $4{ }^{\circ} \mathrm{C}$ cold challenge for $200 \mathrm{~min}$ ( $\mathrm{n}=6$ per group).

C. H\&E staining in iWAT of mice after M2 macrophages injected, with or without SR59230A treatment for 7 days.

D. Western blot analysis of p-(Ser/Thr)-PKA substrate, UCP1, ATGL, phospho- and total HSL in iWAT of mice after M2 macrophages injected, with or without SR59230A treatment for 7 days. E. Glycerol levels in iWAT of mice after M2 macrophages injected, with or without SR59230A treatment for 7 days ( $n=6$ per group). Results were normalized to the total protein levels. F-I. Indirect calorimetry performed in a CLAMS system after bilateral s.c. M2 macrophages injected, with or without SR59230A treatment for 7 days. $(\mathrm{F}) \mathrm{O}_{2}$ consumption profile of mice during a 12-h light-dark cycle. (G) Histogram representative of whole day and light and dark periods of the results shown in panel E. $(\mathrm{H})$ Heat generation profile of mice during a 12-h light-dark cycle. (I) Histogram representative of whole day and light and dark periods of the results shown in panel $\mathrm{G}$. and injectedred cell type as covariate and using multiple comparison to test for differences in individual time points. *represent M2 Ad-GFP+vehicle vs. M2 Ad-Slit3+vehicle, \# represent M2 Ad-Slit3+vehicle vs. M2 Ad-Slit3+SR59230A. $* * * \mathrm{p}<0.001, * * * * \mathrm{p}<0.0001$. 
A

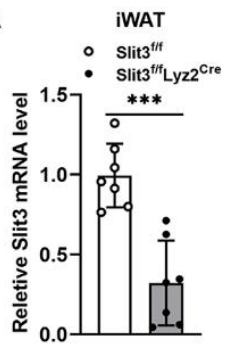

B Slit3 level (iWAT) - Slit3 $^{\text {fif }}$ - Slit3 ${ }^{\text {fif }}$ Lyz2 $^{\text {cre }}$

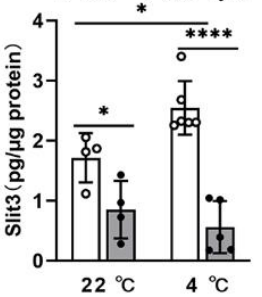

C

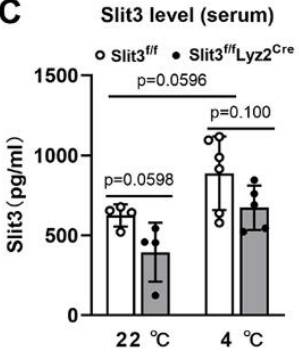

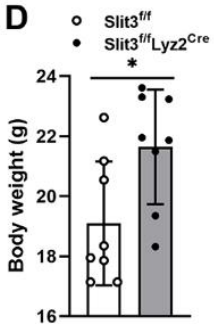

E

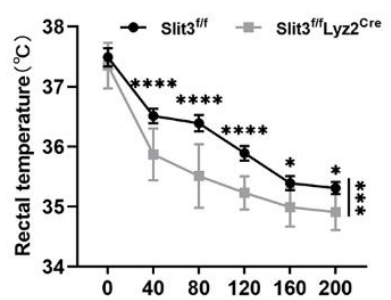

G
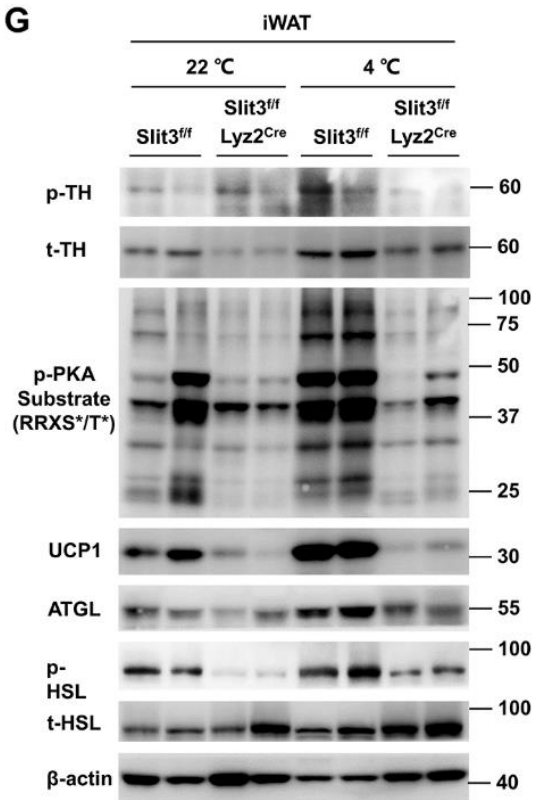

$\mathbf{F}$
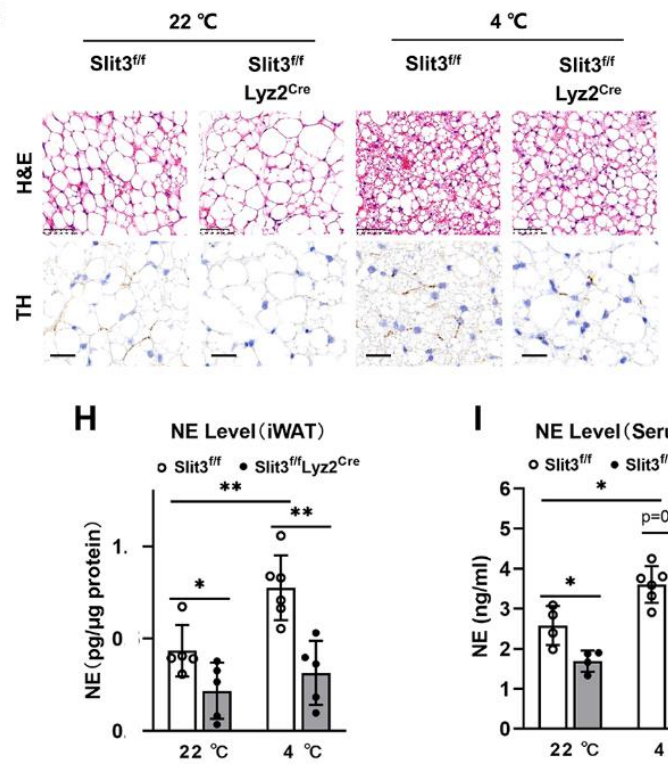

I NE Level(Serum) o Slit3 ${ }^{\text {fff }}$ - Slit3 $3^{\text {fff }}$ Lyz2 ${ }^{\text {Cre }}$
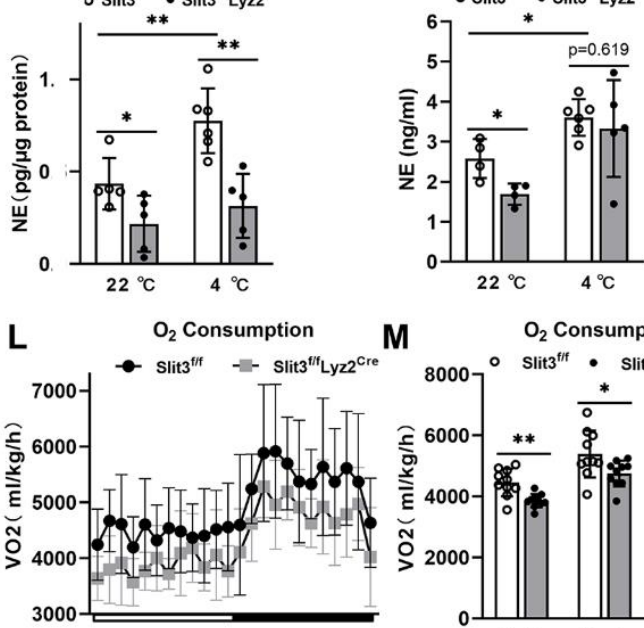

$\mathrm{O}_{2}$ Consumption
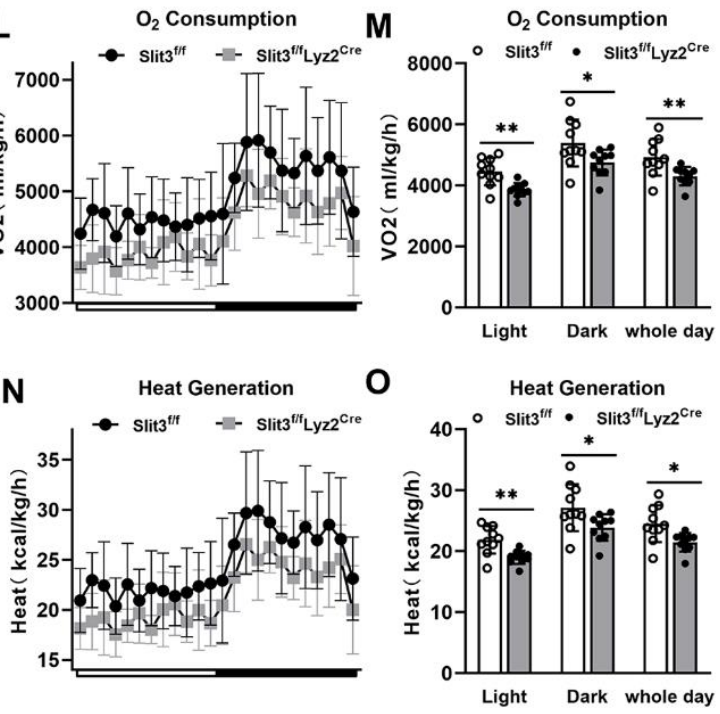
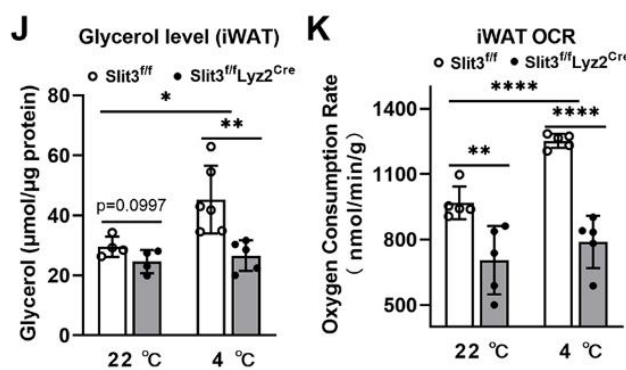

Figure 5: Monocytic deletion of Slit3 impaires thermogenesis and increases weight gain

A. Gene expression of Slit 3 in iWAT from Slit $3^{\mathrm{fff}}$ and Slit $3^{\mathrm{f} / \mathrm{L}} \mathrm{Lyz}^{\mathrm{Cre}}$ mice ( $\mathrm{n}=7$ per genotype). B. Slit3 levels in iWAT of Slit3 ${ }^{\mathrm{f} / \mathrm{f}}$ and Slit $3{ }^{\mathrm{f} / \mathrm{L}} \mathrm{Lyz} 2^{\mathrm{Cre}}$ mice that were housed at $22^{\circ} \mathrm{C}$ or exposed to $4{ }^{\circ} \mathrm{C}$ for $24 \mathrm{~h}$ was determined by ELISA analyze ( $\mathrm{n}=4-6$ per genotype). Results were normalized to the total protein levels. 
for $24 \mathrm{~h}$ was determined by ELISA analyze ( $\mathrm{n}=4-6$ per genotype).

D. Body weight of Slit $3^{f / f}$ and Slit $3^{\mathrm{f} / \mathrm{L}} \mathrm{Lyz} 2^{\mathrm{Cre}}$ mice ( $\mathrm{n}=7$ per group).

E. Rectal temperature measurements of Slit ${ }^{\mathrm{f} / \mathrm{f}}$ and Slit ${ }^{\mathrm{f} / \mathrm{L}} \mathrm{Lyz}^{\mathrm{Cre}}$ mice bred at $22{ }^{\circ} \mathrm{C}$ and subjected to $4{ }^{\circ} \mathrm{C}$ cold challenge ( $\mathrm{n}=10$ per genotype).

F. H\&E staining, IHC staining with anti-TH antibody in iWAT isolated from Slit3 $3^{\mathrm{f} / \mathrm{f}}$ and Slit $3^{\mathrm{f} / \mathrm{L}} \mathrm{Lyz} 2^{\mathrm{Cre}}$ mice. Scale bar: up low $100 \mu \mathrm{m}$; bottom row $20 \mu \mathrm{m}$. phospho- and total HSL in whole-cell extracts of iWAT of Slit3 ${ }^{\mathrm{f} / \mathrm{f}}$ and Slit $3^{\mathrm{f} / \mathrm{Lyz}} 2^{\mathrm{Cre}}$ mice that were housed at $22^{\circ} \mathrm{C}$ or exposed to $4^{\circ} \mathrm{C}$ for $24 \mathrm{~h}$.

H. NE levels in iWAT of Slit3 ${ }^{\mathrm{f} / \mathrm{f}}$ and $\mathrm{Slit} 3^{\mathrm{f} / \mathrm{L}} \mathrm{Lyz} 2^{\mathrm{Cre}}$ mice ( $\mathrm{n}=5-6$ per genotype). Results were normalized to the total protein levels.

I. NE levels in serum of Slit $3^{\mathrm{fff}}$ and Slit ${ }^{\mathrm{ff} f} \mathrm{Lyz} 2^{\mathrm{Cre}}$ mice ( $\mathrm{n}=4-6$ per genotype).

J. Glycerol levels in iWAT of Slit $3^{\mathrm{f} / \mathrm{f}}$ and $\mathrm{Slit}^{\mathrm{ff} / \mathrm{Lyz}} 2^{\mathrm{Cre}}$ mice that were housed at $22^{\circ} \mathrm{C}$ or exposed to $4^{\circ} \mathrm{C}$ for $24 \mathrm{~h}$ ( $\mathrm{n}=4-6$ per genotype). Results were normalized to the total protein levels.

$\mathrm{K}$. Oxygen consumption rate (OCR) of iWAT isolated from Slit3 ${ }^{\mathrm{f} / \mathrm{f}}$ and $\mathrm{Slit} 3^{\mathrm{f} / \mathrm{L}} \mathrm{Lyz} 2^{\mathrm{Cre}}$ mice was measured and shown ( $\mathrm{n}=5$ per genotype).

L-O. Indirect calorimetry performed in a CLAMS system of Slit3 ${ }^{\mathrm{f} / \mathrm{f}}$ and Slit3 ${ }^{\mathrm{f} / \mathrm{L}} \mathrm{Lyz}^{\mathrm{Cre}}$ mice. $(\mathrm{L}) \mathrm{O}_{2}$ consumption profile of mice during a 12-h light-dark cycle. (M)Histogram representative of whole day and light and dark periods of the results shown in panel L. (N) Heat generation profile of mice during a 12-h light-dark cycle. (O) Histogram representative of whole day and light and dark periods of the results shown in panel N. ( $\mathrm{n}=10$ per genotype).

Data are presented as mean \pm SEM. Data in (E) are analyzed using two-way ANOVA using time and temperature as covariate and using multiple comparison to test for differences in individual time points. Data in (A-D and H-O) are analyzed using student's $\mathrm{t}$ test for comparisons. ${ }^{*} \mathrm{p}<0.05$, $* * \mathrm{p}<0.01, * * * \mathrm{p}<0.001, * * * * \mathrm{p}<0.0001$. 
A

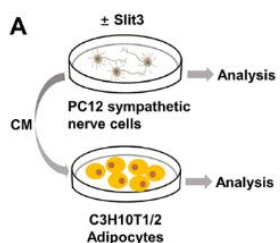

B
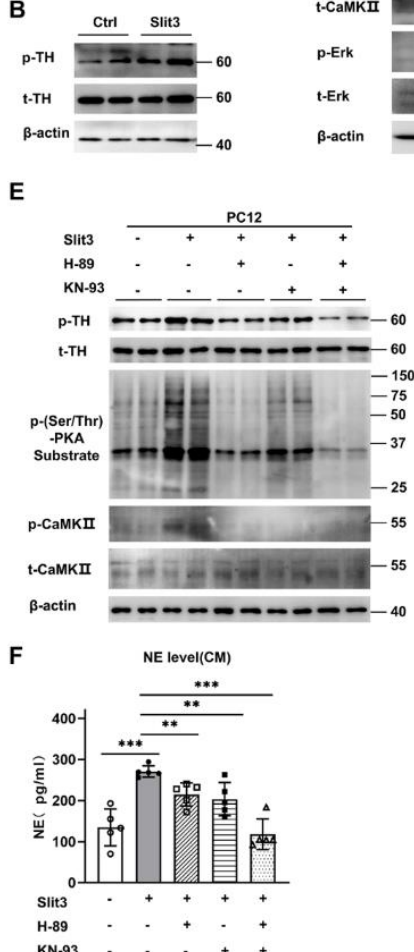
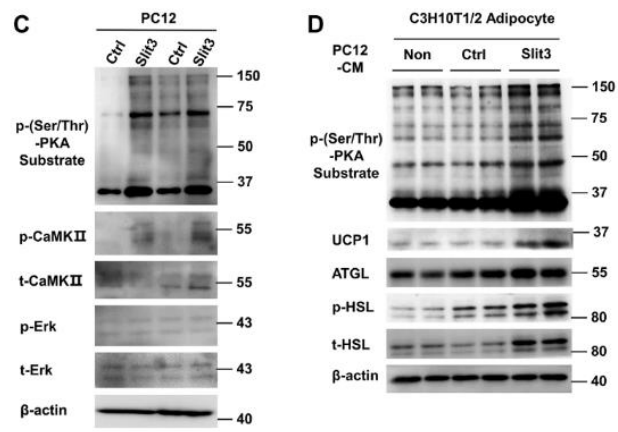

\section{G}

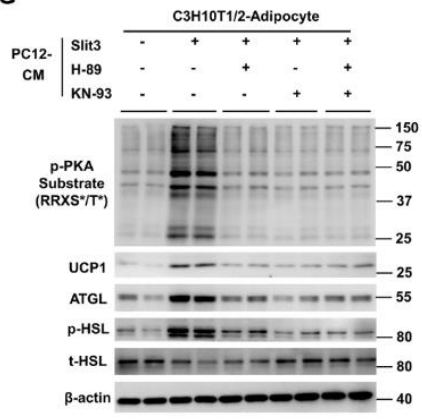

Figure 6: Slit3 stimulates the phosphorylation of TH via PKA/CaMKII in PC12 sympathetic nerve cells

A. Experimental approach to evalute the effect of Sli3-treated PC12 sympathetic nerve cells on C3H10T1/2 adipocytes.

B. Western blot analysis of phospho- and total TH in PC12 cells with PBS (control) or Slit3 $(1 \mu \mathrm{g} / \mathrm{ml})$ treatment for $24 \mathrm{~h}$.

C. Western blot analysis of p-(Ser/Thr)-PKA substrate, phospho- and total CaMKII, phospho- and total Erk in PC12 cells with PBS (control) or Slit3 $(1 \mu \mathrm{g} / \mathrm{ml})$ treatment for $24 \mathrm{~h}$.

D. Western blot analysis of p-(Ser/Thr)-PKA substrate, UCP1, ATGL, phospho- and total HSL in C3H10T1/2 adipocytes upon 24h-treatment with conditioned medium from PC12 cells in panel C.

E. Slit3-stimulated phosphorylation of TH was suppressed by inhibiting CaMKII with treatment of $10 \mu \mathrm{M}$ KN-93 or inhibiting PKA with treatment of $10 \mu \mathrm{M} \mathrm{H}-89$ in PC12 cells.

F. NE levels in PC12 CM with treatment as directed for 24 hours ( $\mathrm{n}=5$ per group).

G. Western blot analysis for p-PKA substrate (RRXS*/T*), UCP1, ATGL, phospho- and total HSL in $\mathrm{C} 3 \mathrm{H} 10 \mathrm{~T} 1 / 2$ adipocytes upon $24 \mathrm{~h}$-treatment with conditioned medium from PC12 cells in panel E.

Data are presented as mean \pm SEM. Student's $t$ test was used for comparisons. ${ }^{*} \mathrm{p}<0.05,{ }^{* *} \mathrm{p}<$ $0.01, * * * \mathrm{p}<0.001, * * * * \mathrm{p}<0.0001$. 
Figure 7
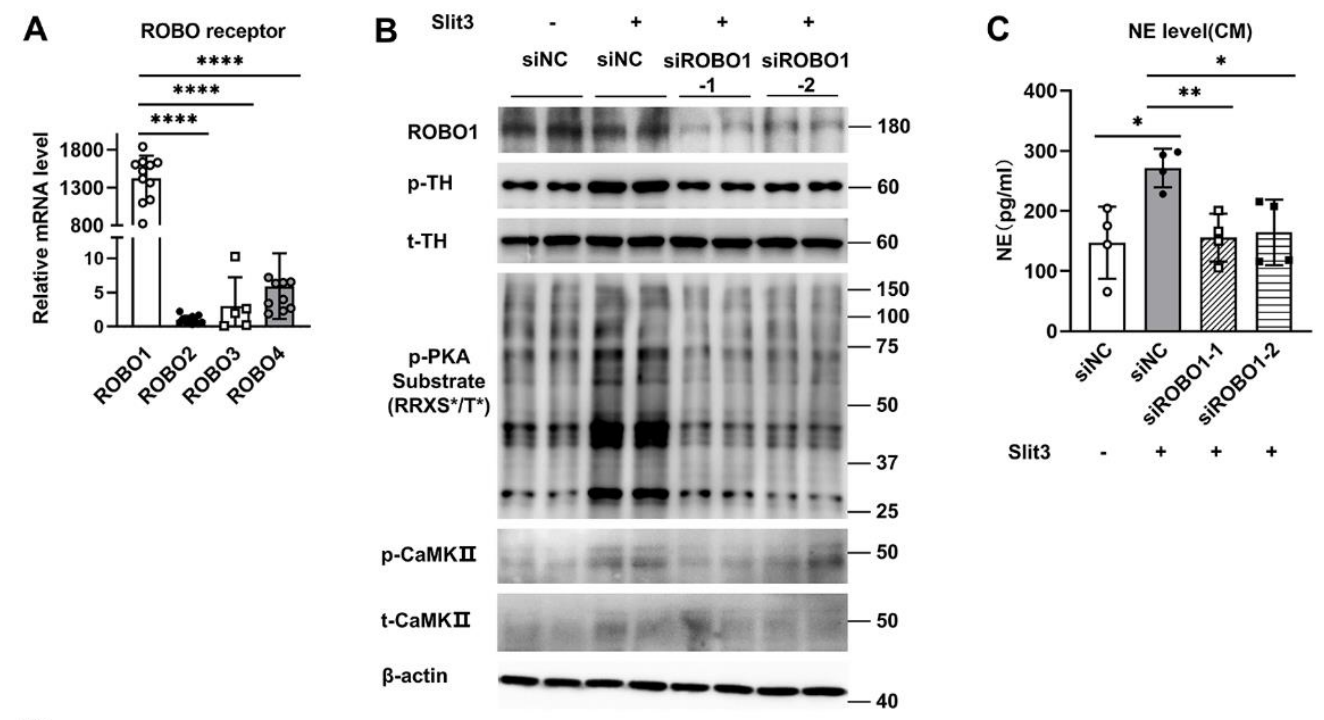

D

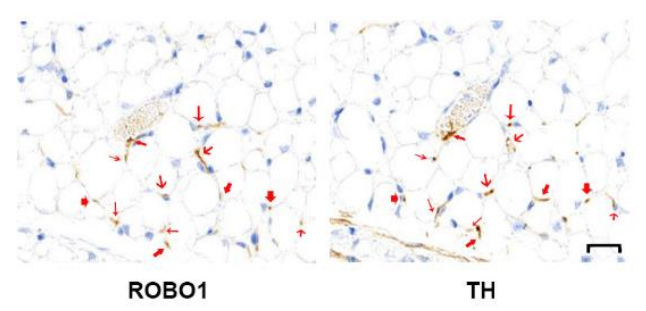

Figure 7: ROBO1 is the receptor for Slit3 to stimulates the phosphorylation of TH and NE production

A. Gene expression of $\mathrm{ROBO} 1, \mathrm{ROBO} 2, \mathrm{ROBO} 3$ and $\mathrm{ROBO} 4$ in $\mathrm{PC} 12$ sympathetic nerve cells (n $=5-11$ per group).

B. Western blot analysis for ROBO1, phospho- and total TH, p-PKA substrate (RRXS*/T*), phospho- and total CaMKII in PC12 cells upon treatment of siNC or siROBO1, with or without Slit3 for $24 \mathrm{~h}$.

C. NE levels in PC12 CM upon treatment of siNC or siROBO1, with or without Slit3 for $24 \mathrm{~h}$ (n $=4$ per group).

D. Staining for ROBO1 and TH by immunochemistry on sequential sections. Arrows with the same shape indicate the same site. Scale bar: $20 \mu \mathrm{m}$.

Data are presented as mean \pm SEM. Student's $t$ test was used for comparisons. $* \mathrm{p}<0.05, * * \mathrm{p}<$ $0.01, * * * \mathrm{p}<0.001,{ }^{* * * *} \mathrm{p}<0.0001$. 
A

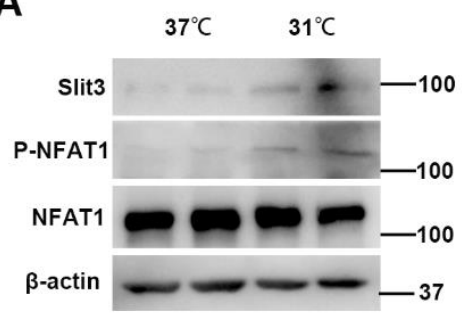

C

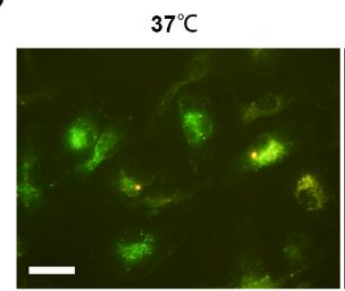

B

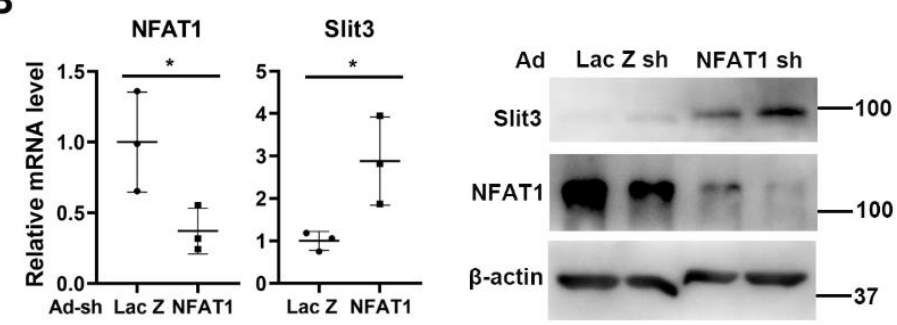

D

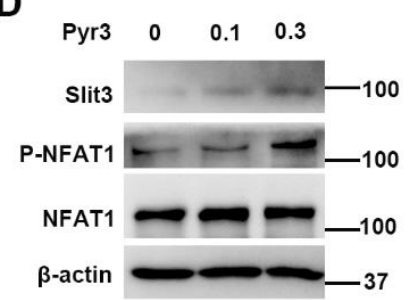

974

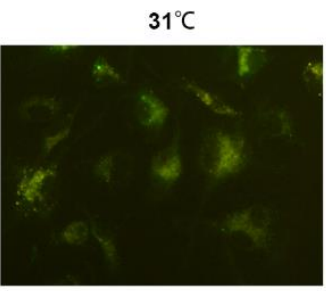

Figure 8: NFAT1 negatively regulate Slit3 expression in M2 macrophage.

A: Western blot determine the levels of Slit3, phosphorylated Slit3 (P-Slit3) and Slits in BMDM M2 macrophages after incubating at $31^{\circ} \mathrm{C}$.

B: NFAT1 were knockdown by adenovirus-carried shRNA, and levels of NFAT1 and Slit3 were determined by qPCR and western blot. Data were collected from 3 individual experiments and analyzed by student's $\mathrm{t}$ test. $* \mathrm{p}<0.05$.

C: BMDM M2 macrophages were at $37^{\circ} \mathrm{C}$ or $31^{\circ} \mathrm{C}$ for 60 minutes followed by staining with $4 \mu \mathrm{M}$ calcium indicator Fluo-3 AM for 60 minutes. Images were taken with microscopy. D: BMDM M2 were treated with Pyr3 at concentrations of 0.1 or $0.3 \mu \mathrm{M}$ for 60 minutes, and levels of Slit3, P-NFAT1, and NFAT1 were determined. 


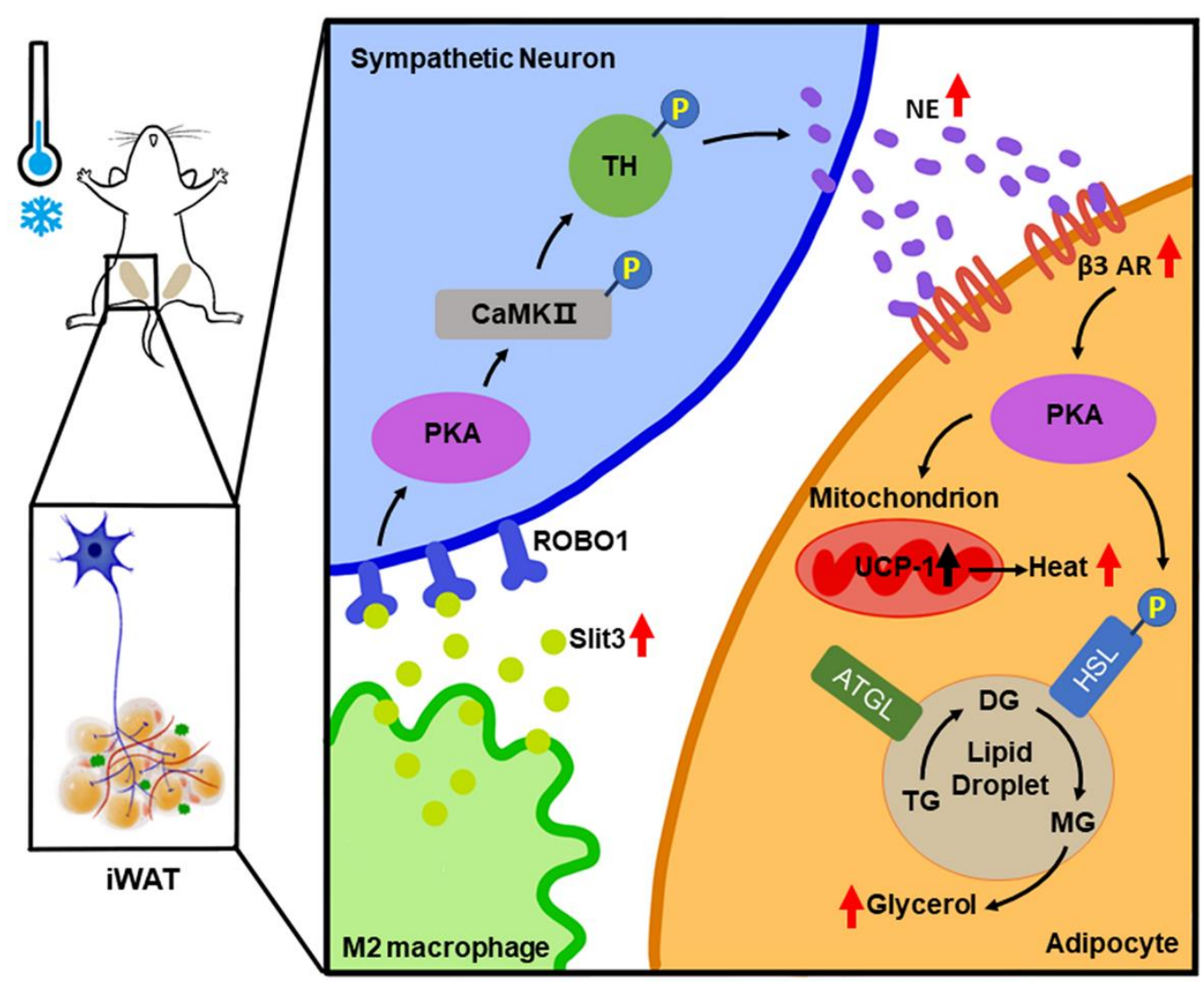

Figure 9: Schematic model for the functions of Slit3 in adipose tissue.

When encountered with cold, percentage of M2 macrophages in iWAT was increased and more Slit3 was secreted. Slit3 activated the PKA signaling pathway in sympathetic neurons through the ROBO1 receptor, and promoted the synthesis and release of NE through the phosphorylation of TH via PKA/CaMKII pathway. NE subsequently activated the PKA signaling pathway in adipocytes through $\beta 3$ adrenergic receptor. In adipocytes, activated PKA enhanced lipolysis and glycerol release through phosphorylation of HSL while promoted the expression of UCP1 for uncoupling respiration, so as to maintain the adaptive thermogenesis under cold environment. 


\section{Figures}

A

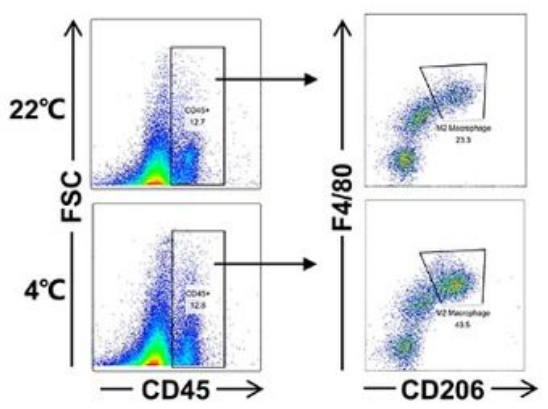

C

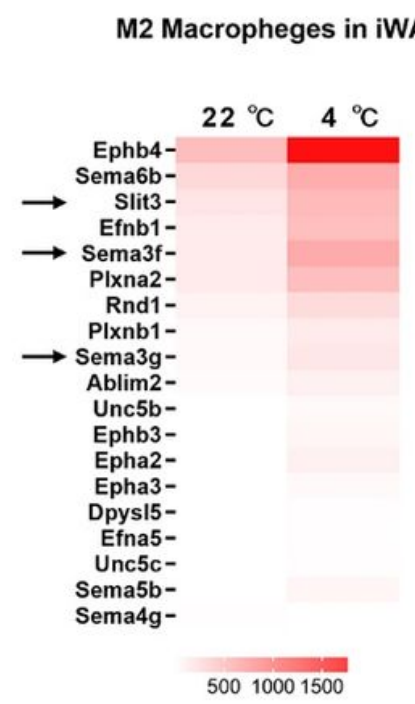

$\longrightarrow$ Secretory factor
M2 Macropheges in iWAT

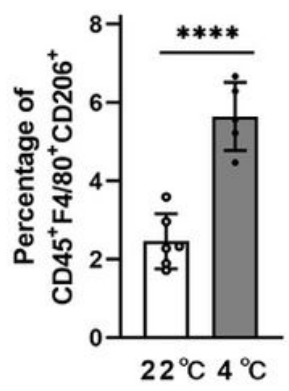

D

M2 Macropheges in iWAT

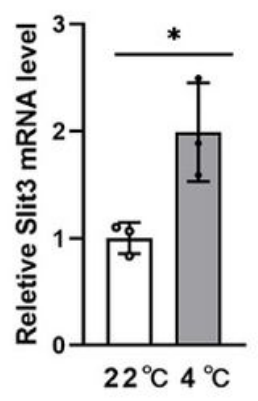

G

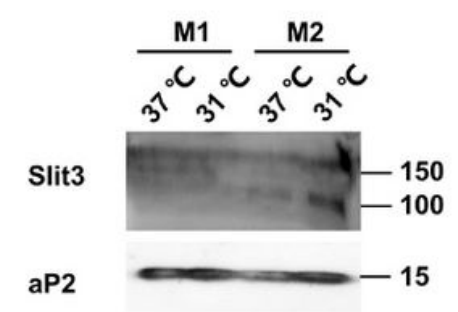

$\beta$-actin

E
B
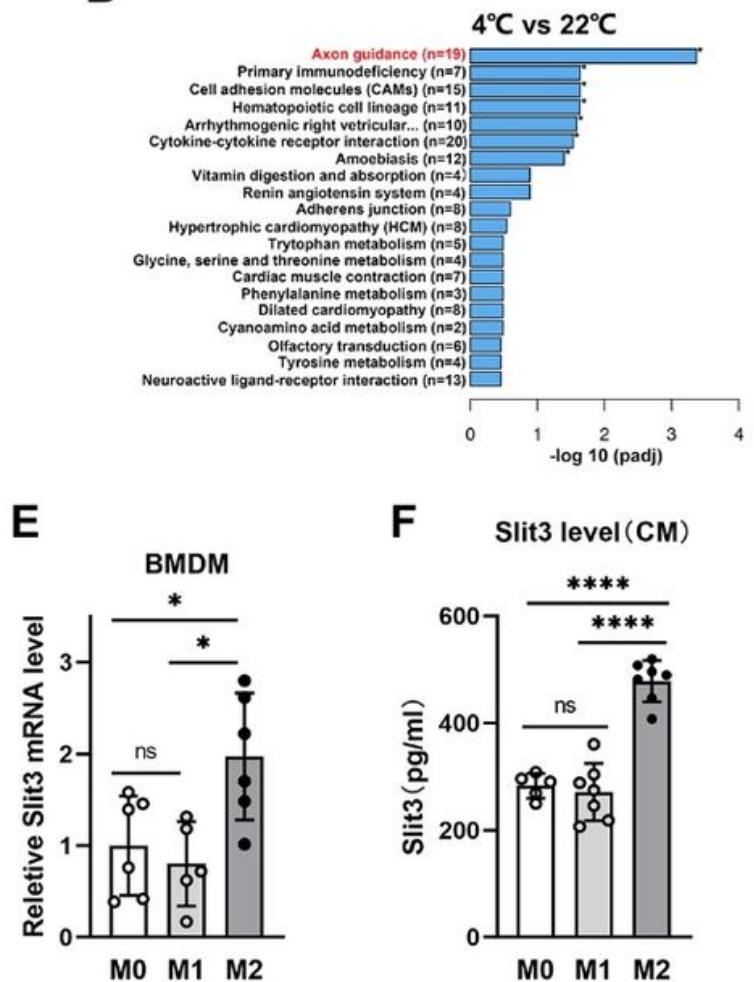

F

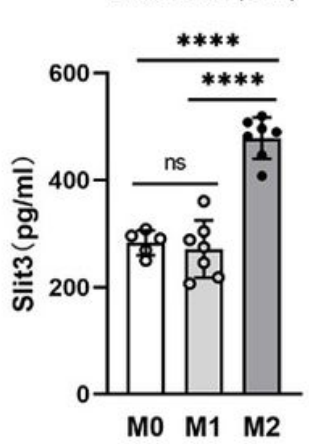

H

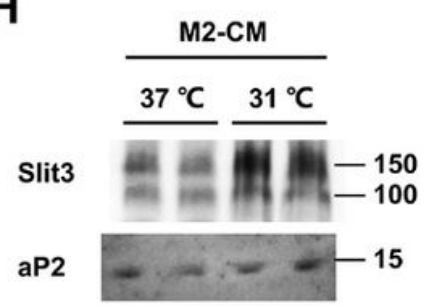

\section{Figure 1}

Identification of Slit3 as a cold induced secreted protein by M2 macrophages in iWAT A. Flow cytometry analysis for M2 macrophages (CD45+F4/80+CD206+) in iWAT from mice housed at 22 $₫$ or exposed to 4区 for $3 d(n=6 / 5)$. B C. Enrichment analysis of KEGG pathway(B) and heat map (C) showing relative mRNA levels in M2 macrophages in iWAT from mice housed at $22 \bigotimes$ or exposed to $4 \llbracket$ for $3 d$ ( $n=1$ per group). The heat map based on fragments per kilobase of exon model per million mapped fragments 768 (FPKM). D. Gene expression of Slit3 in M2 macrophages in iWAT from mice housed at 22\ or exposed to $4 \rrbracket$ for $3 \mathrm{~d}$ ( $n=3$ per group). M2 macrophages were collected by FACS on total SVF pooled from 30 mice in each group, the experiment was repeated for 3 times. E. Gene expression of Slit3 in M0, M1 and M2 Macrophages ( $n=56$ per group). F. Slit3 levels in conditioned medium (CM) from M0, M1 and M2 macrophages was determined by ELISA analyze ( $n=57$ per group). G. Western blotting against Slit3, aP2 in M1 and M2 macrophages. H. Western blotting against Slit3 from concentrated M2 macrophages CM. 
Data are presented as mean \pm SEM. Student's $t$ test was used for comparisons. ${ }^{*} p<0.05, * \star p<7780.01$, $\star \star \star ~ p<0.001, * \star \star \star p<0.0001$.
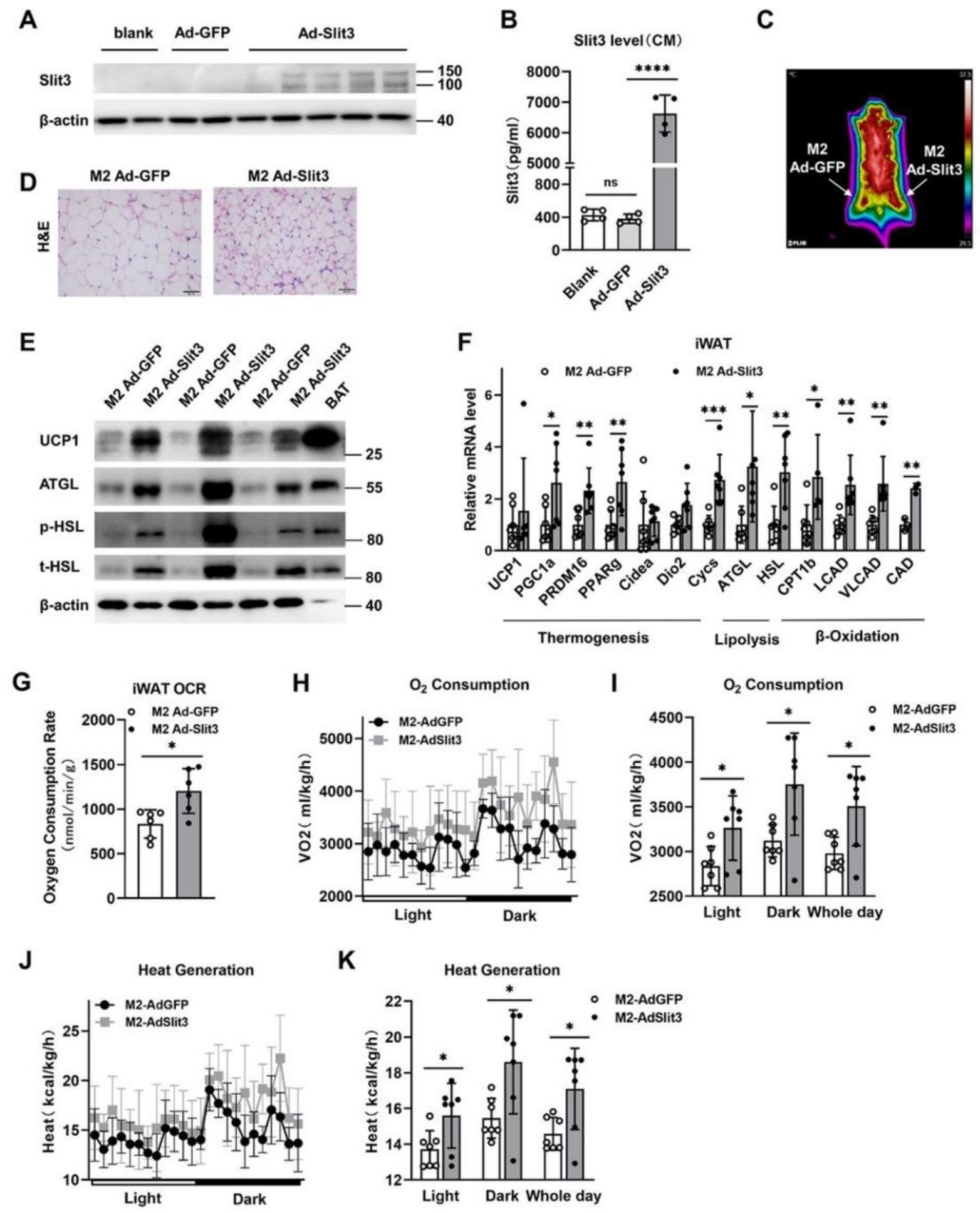

\section{Figure 2}

M2 macrophages with Slit3 overexpressed increases thermogenic capacity of iWAT A. Western blotting against Slit3 in untreated or Slit3 overexpressed adenovirus infected M2 macrophages. B. Slit3 levels in CM from untreated or Slit3 overexpressed adenovirus infected M2 macrophages was determined by 
ELISA analyze ( $\mathrm{n}=4$ per group). C. The whole body temperature of mice after $\mathrm{M} 2$ macrophages injected was analyzed by a thermal imaging system. D. H\&E staining of iWAT collected from mice after M2 macrophages injected. E. Western blot analysis of UCP1, phospho and total HSL and ATGL in iWAT of mice after M2 macrophages injected. F. qPCR analysis of thermogenesis, lipolysis and $\beta$ Oxidation genes in iWAT of mice after M2 macrophages injected ( $n=58$ per group). G. Oxygen consumption rate (OCR) of iWAT isolated from mice after M2 macrophages injected was measured and shown ( $n=6$ per group). Data are presented as mean \pm SEM. Student's $t$ test was used for comparisons. ${ }^{\star} p<0.05,{ }^{\star \star} p<0.01, * \star \star p<$ $0.001, * * * * p<0.0001$

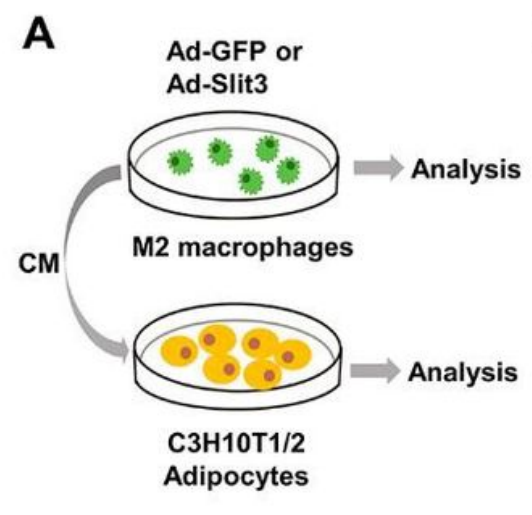

B
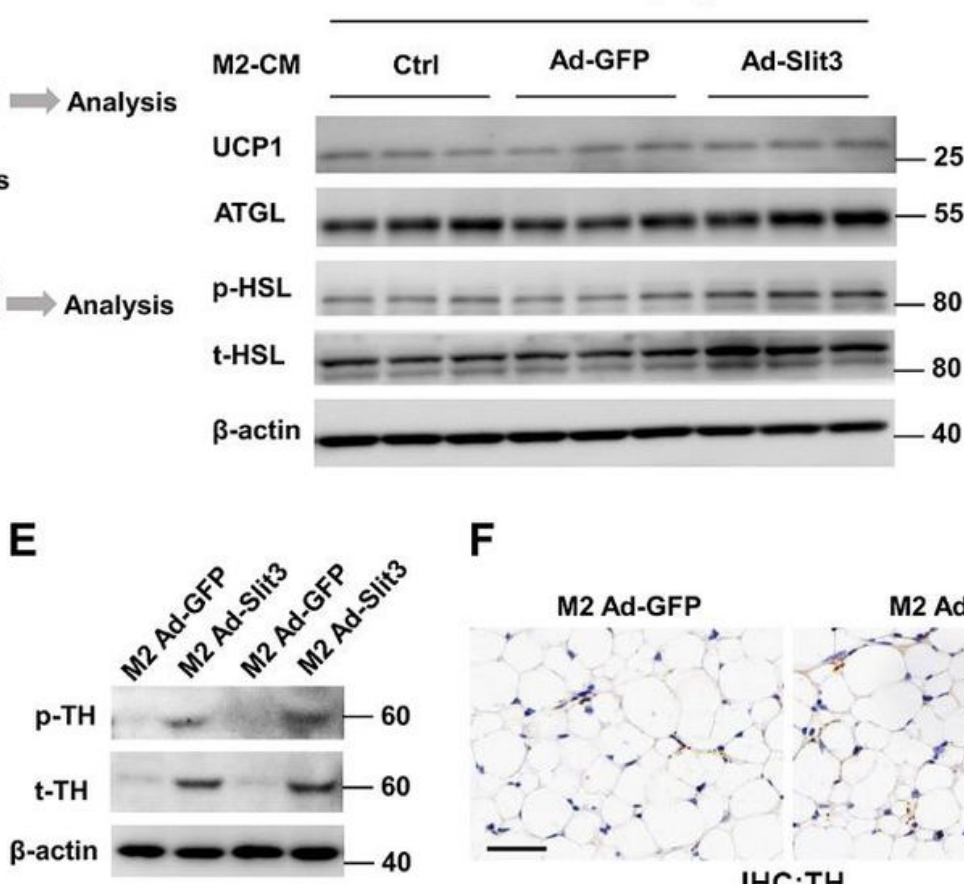

D iWAT

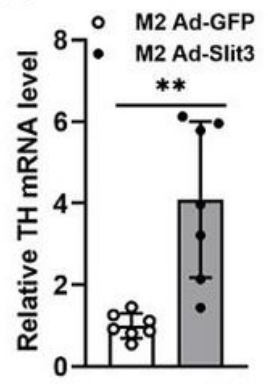

H NE Level(iWAT)

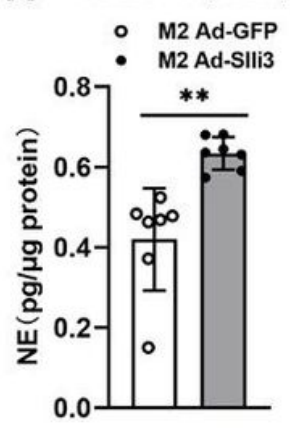

I NE Level(Serum)

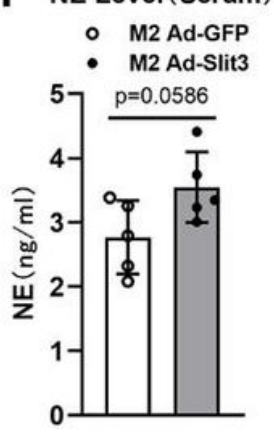

$\mathbf{F}$

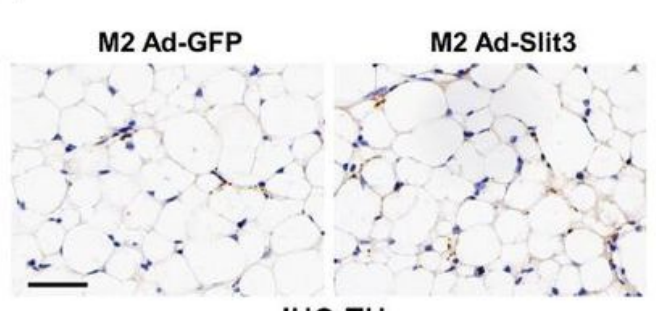

IHC:TH
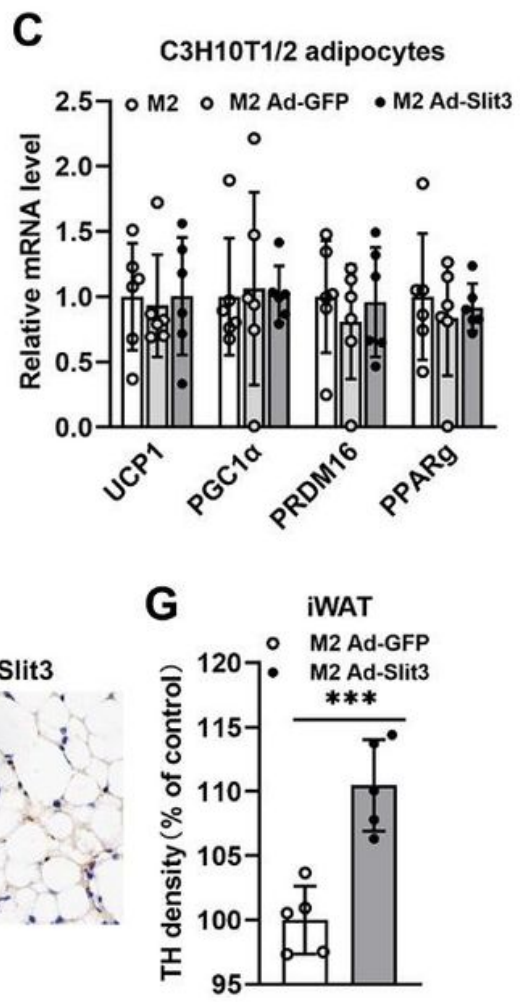

\section{Figure 3}

M2 macrophage secreted Slit3 activates TH activity in sympathetic nerves A. Experimental approach to evalute the effect of Slit3 overexpressed M2 macrophages on C3H10T1/2 adipocytes. B. Western blot analysis for UCP1, ATGL and phospho and total HSL in C3H10T1/2 adipocytes upon 24h treatment with conditioned medium from M2 macrophages. C. Normalized gene expression in C3H10T1/2 adipocytes 
upon $24 \mathrm{~h}$ treatment with conditioned medium from M2 macrophages ( $\mathrm{n}=6$ per group). D. qPCR analysis of TH expression in iWAT of mice after M2 macrophages injected ( $n=7$ per group). E. Western blot analysis of phospho and total TH in iWAT of mice after M2 macrophages injected. F. IHC staining with anti TH antibody in iWAT of mice after M2 macrophages injected. Scale bar: $20 \mu \mathrm{m}$. G. Density analysis and statistics of the results shown in panel $E$ ( $n=5$ per group). $H$. NE levels in iWAT of mice after M2 macrophages injected. Results were normalized to the total protein levels ( $n=7$ per group). I. NE levels in serum of mice after M2 macrophages injected ( $n=5$ per group). Data are presented as mean \pm SEM. Student's $t$ test was used for comparisons. ${ }^{*} p<0.05$, ** $p<0.01$, *** $p<0.001$, **** $p<0.0001$.

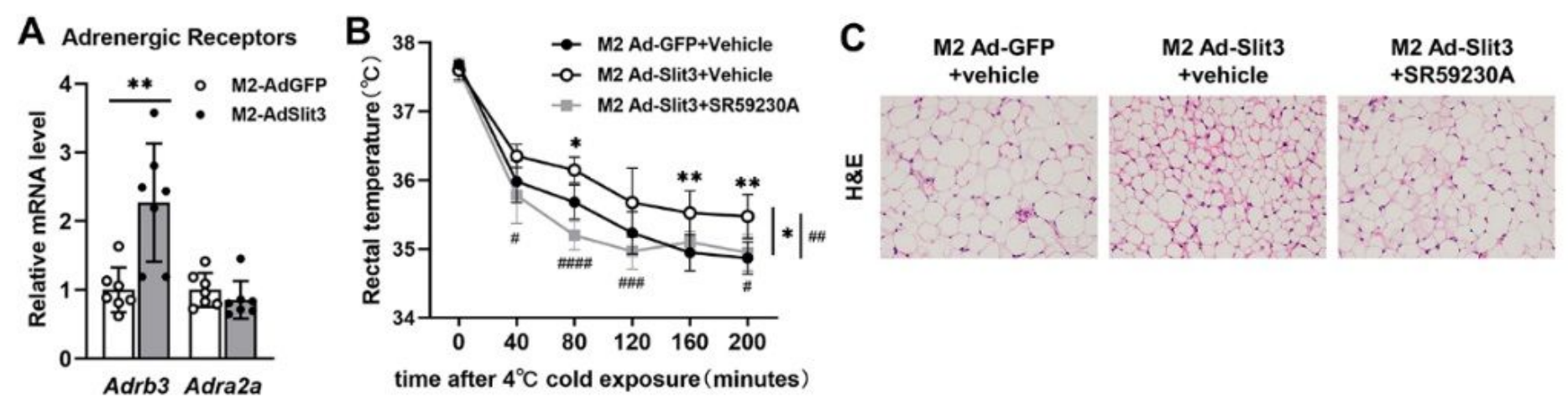

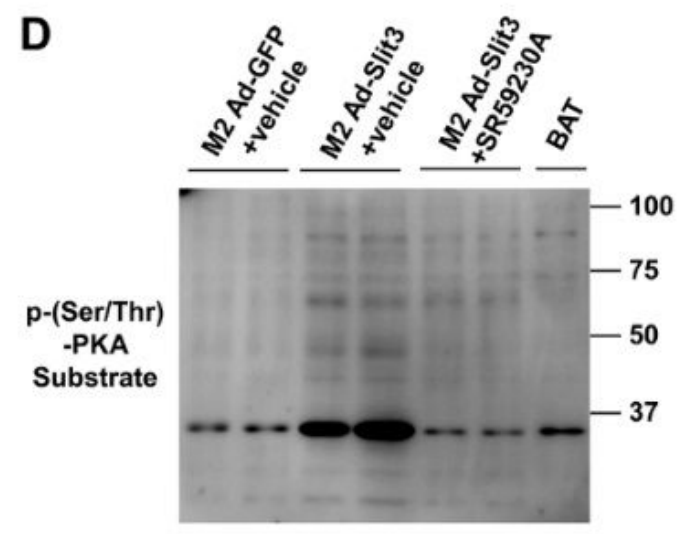

UCP1

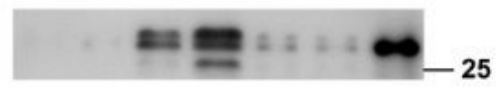

ATGL

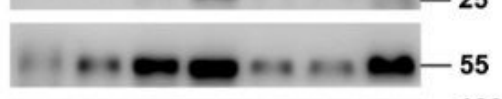

p-HSL

t-HSL

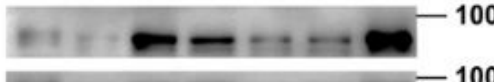

$\beta$-actin

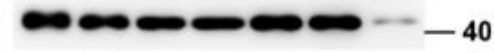

E Glycerol Level( iWAT)

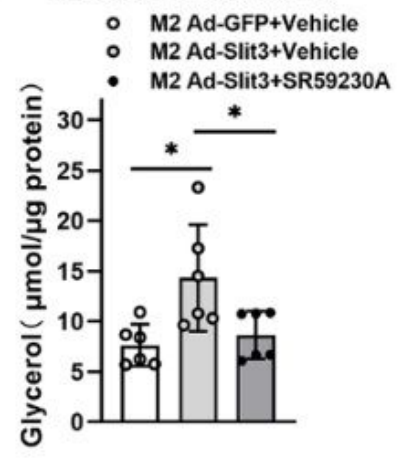

$\mathbf{F}$

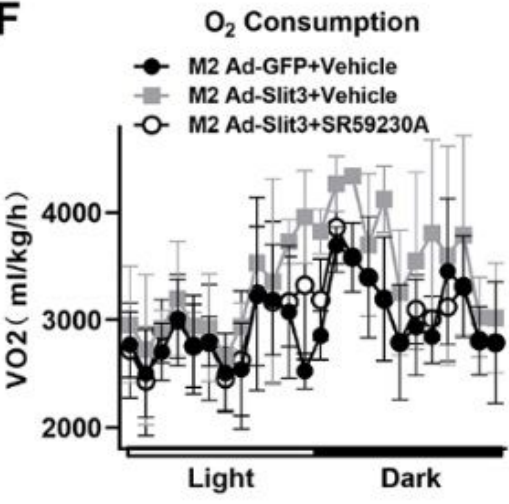

H

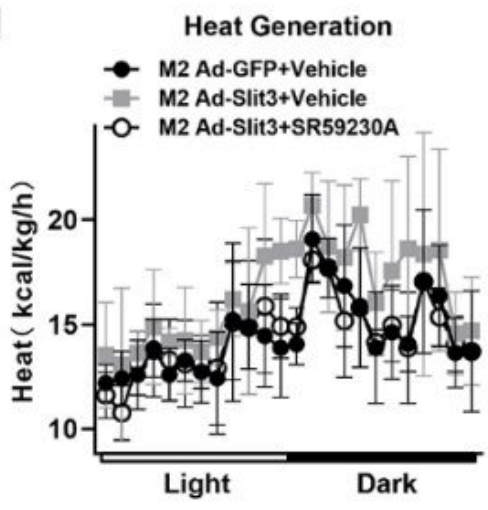

G $\quad \mathrm{O}_{2}$ Consumption

- M2 Ad-GFP+Vehicle

- M2 Ad-Slit3+Vehicle

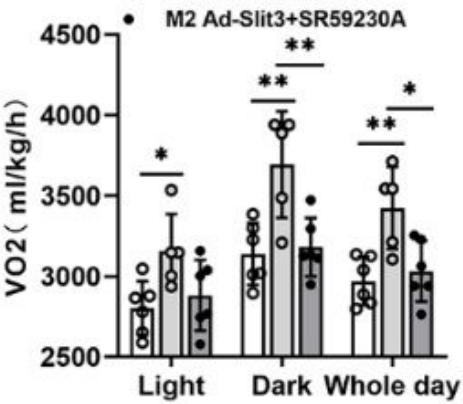

I Heat Generation

○ M2 Ad-GFP+Vehicle

- M2 Ad-Slit3+Vehicle

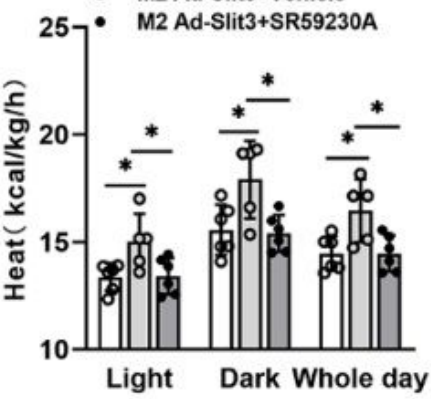




\section{Figure 4}

Thermogenic activity induced by Slit3 from M2 macrophage depends on NE/B3 AR A. qPCR analysis of adrenergic receptor genes, namely, Adrb3 and Adra2a, in iWAT of mice after M2 macrophages injected ( $n=7$ per group). B. Rectal temperature measurements of mice after M2 macrophages injected, with or without SR59230A treatment for 7 days, which bred at $22^{\circ} \mathrm{C}$ and subjected to $4{ }^{\circ} \mathrm{C}$ cold challenge for $200 \mathrm{~min}$ ( $\mathrm{n}=6$ per group). C. H\&E staining in iWAT of mice after M2 macrophages injected, with or without SR59230A treatment for 7 days. D. Western blot analysis of p--(Ser/ PKA substrate, UCP1, ATGL, phospho and total HSL in iWAT of mice after M2 macrophages injected, with or without SR59230A treatment for 7 days. E. Glycerol levels in iWAT of mice after M2 macrophages injected, with or without SR59230A treatment for 7 days ( $n=6$ per group). Results were normalized to the total protein levels. F I. Indirect calorimetry performed in a CLAMS system after bilateral s.c. M2 macrophages injected, with or without SR59230A treatment for 7 days. (F)02 consumption profile of mice during a $12 \mathrm{~h}$ light dark cycle. (G) Histogram representative of whole day and light and dark periods of the results shown in panel $E .(H)$ Heat generation profile of mice during a $12 \mathrm{~h}$ light dark cycle. (I) Histogram representative of whole day and light and dark periods of the results shown in panel G. Data are presented as mean \pm SEM. Data in (B) are analyzed using two way ANOVA using time and injectedred cell type as covariate and using multiple comparison to test for differences in individual time points. *represent M2 Ad GFP+vehicle vs. M2 Ad Slit3+vehicle, \# represent M2 Ad Slit3+vehicle vs. M2 Ad Slit3+SR59230A. Data in (A and E I) are analyzed using student's t test for comparisons. ${ }^{*} p<0.05,{ }^{\star \star} p<0.01,{ }^{\star \star \star} p<0.001,{ }^{\star \star \star \star} p<0.0001$. 

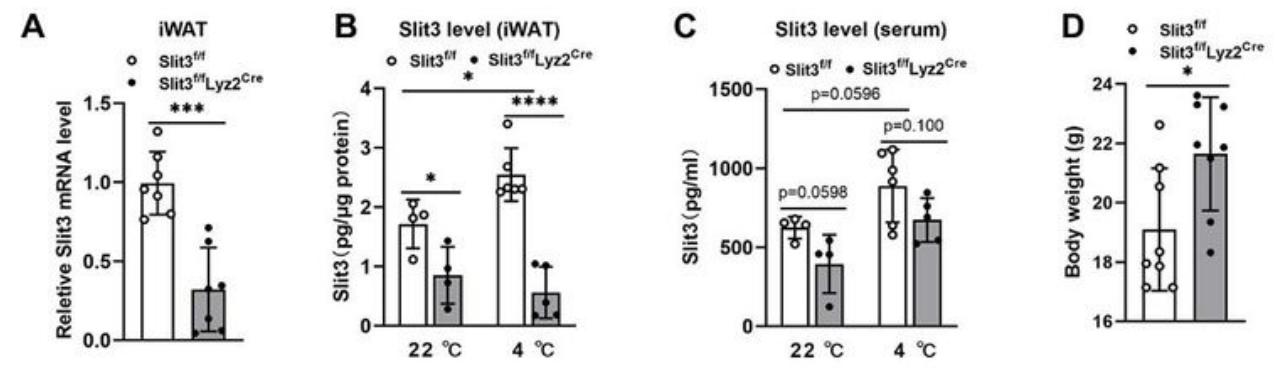

E

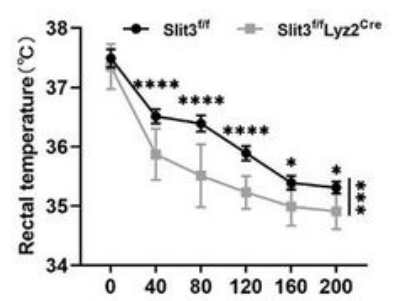

G
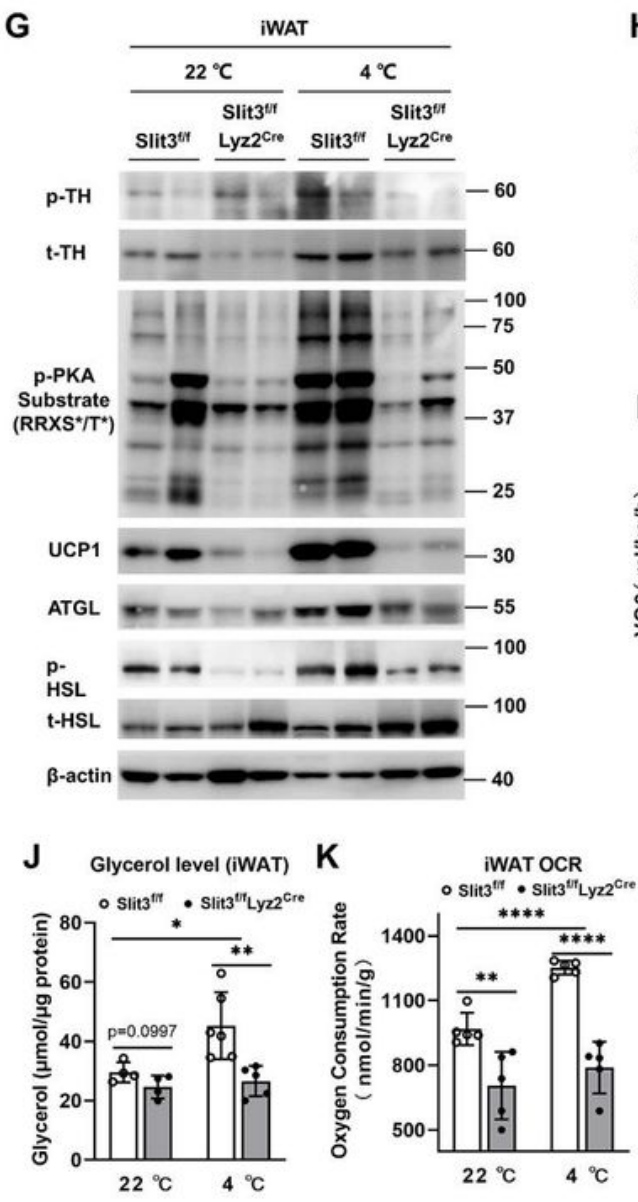

F

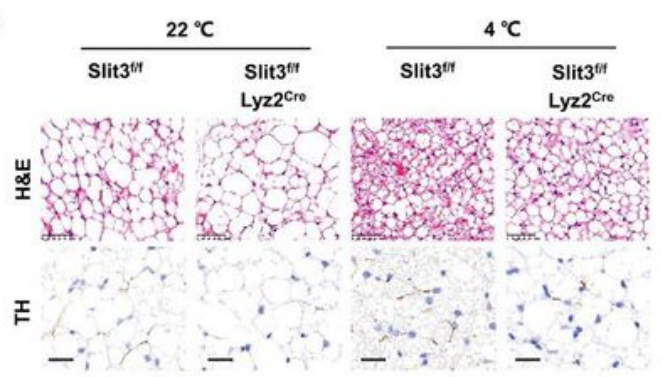

H

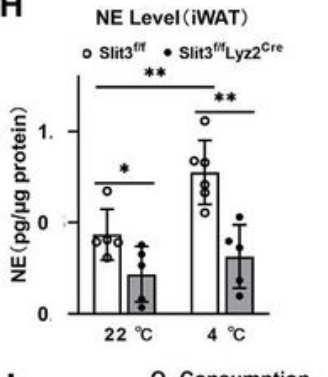

I NE Level(Serum)
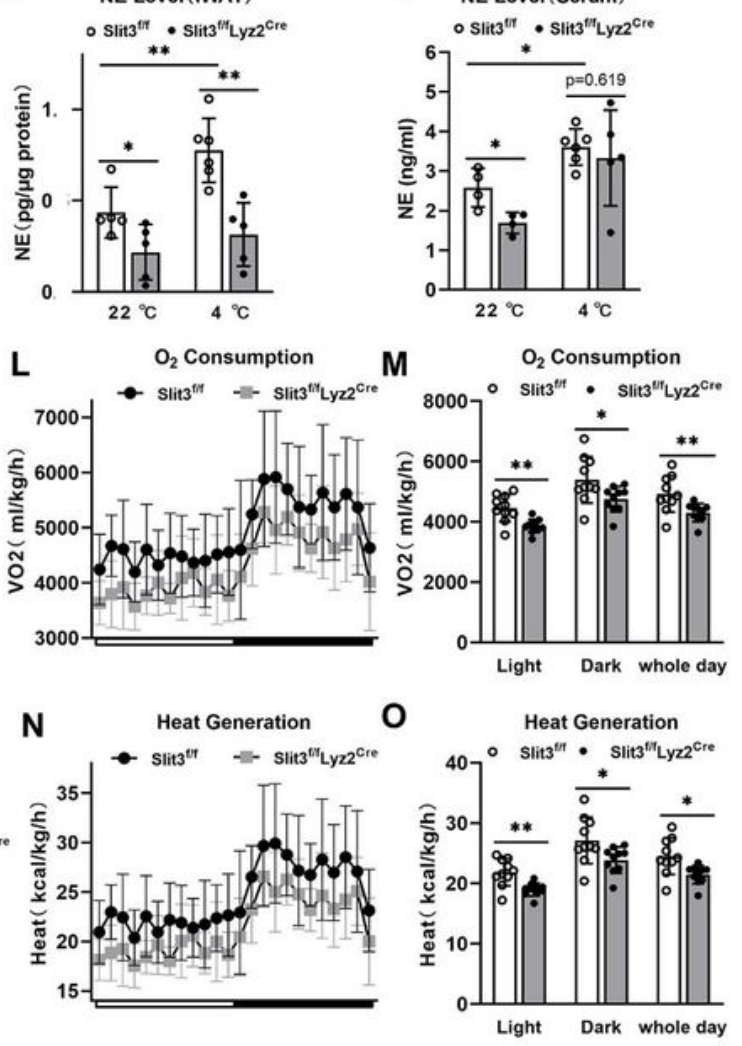

\section{Figure 5}

Monocytic deletion of Slit3 impaires thermogenesis and increases weight gain A. Gene expression of Slit3 in iWAT from Slit3f/f and Slit3f/fLyz2Cre mice ( $n=7$ per genotype). B. Slit3 levels in iWAT of Slit3f/f and Slit3f/fLyz2Cre mice that were housed at 22》 or exposed to $4 \rrbracket$ for $24 \mathrm{~h}$ was determined by ELISA analyze ( $n=46$ per genotype). Results were normalized to the total protein levels. C. Slit3 levels in serum of Slit3f/f and Slit3f/fLyz2Cre mice that were housed at 22 $\nabla$ or exposed to $4 \nabla$ for $24 \mathrm{~h}$ was determined by 
ELISA analyze ( $n=4-6$ per genotype). D. Body weight of Slit3f/ $f$ and Slit3f/fLyz2Cre mice ( $n=7$ per group). E. Rectal temperature measurements of Slit3f/f and Slit3f/fLyz2Cre mice bred at $22{ }^{\circ} \mathrm{C}$ and subjected to $4{ }^{\circ} \mathrm{C}$ cold challenge ( $\mathrm{n}=10$ per genotype). F. H\&E staining, IHC staining with anti-TH antibody in iWAT isolated from Slit3f/f and Slit3f/fLyz2Cre mice. Scale bar: up low $100 \mu \mathrm{m}$; bottom row $20 \mu \mathrm{m}$. G. Western blot analysis of phospho- and total TH, p--PKA substrate (RRXS*/T*), UCP1, ATGL, phosphoand total HSL in whole-cell extracts of iWAT of Slit3f/f and Slit3f/fLyz2Cre mice that were housed at 22》

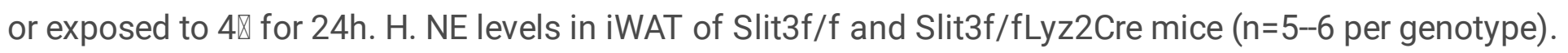
Results were normalized to the total protein levels. I. NE levels in serum of Slit3f/f and Slit3f/fLyz2Cre mice ( $n=4-6$ per genotype). J. Glycerol levels in iWAT of Slit3f/f and Slit3f/fLyz2Cre mice that were housed at $22 \llbracket$ or exposed to $4 \llbracket$ for $24 \mathrm{~h}$ ( $\mathrm{n}=4-6$ per genotype). Results were normalized to the total protein levels. K. Oxygen consumption rate (OCR) of iWAT isolated from Slit3f/f and Slit3f/fLyz2Cre mice was measured and shown ( $n=5$ per genotype). L-O. Indirect calorimetry performed in a CLAMS system of Slit3f/f and Slit3f/fLyz2Cre mice. (L)O2 consumption profile of mice during a 12-h light-dark cycle.

(M)Histogram representative of whole day and light and dark periods of the results shown in panel L. $(\mathrm{N})$ Heat generation profile of mice during a 12--h light-dark cycle. (0) Histogram representative of whole day and light and dark periods of the results shown in panel $N$. ( $n=10$ per genotype). Data are presented as mean \pm SEM. Data in (E) are analyzed using two-way ANOVA using time and temperature as covariate and using multiple comparison to test for differences in individual time points. Data in (A-D and $\mathrm{H}-\mathrm{-O})$ are analyzed using student's $t$ test for comparisons. ${ }^{*} p<0.05,{ }^{\star \star} p<0.01,{ }^{\star \star \star} p<0.001,{ }^{\star \star \star \star} p<0.0001$. 

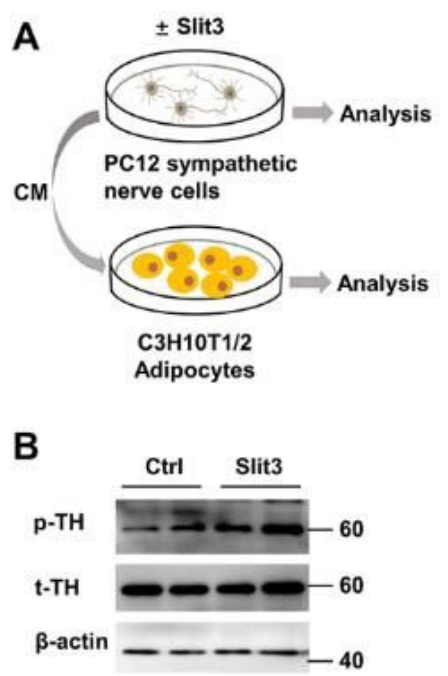

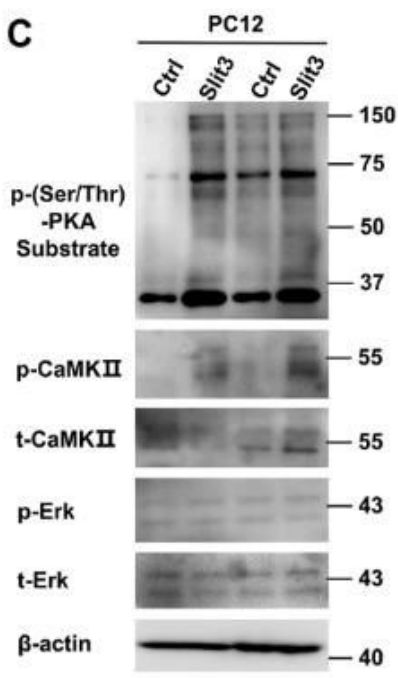

G

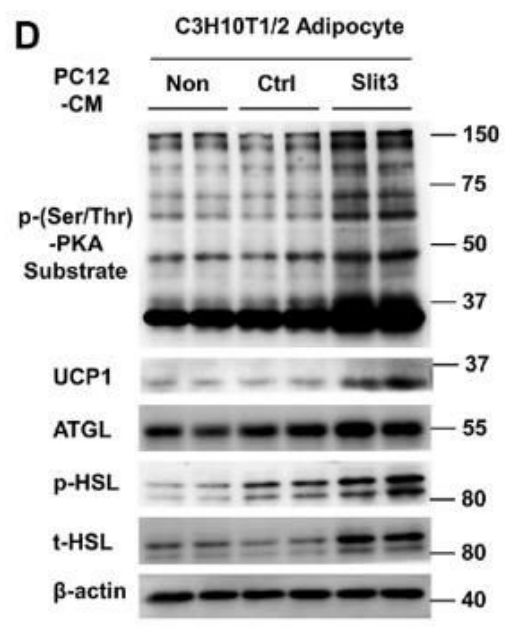

E
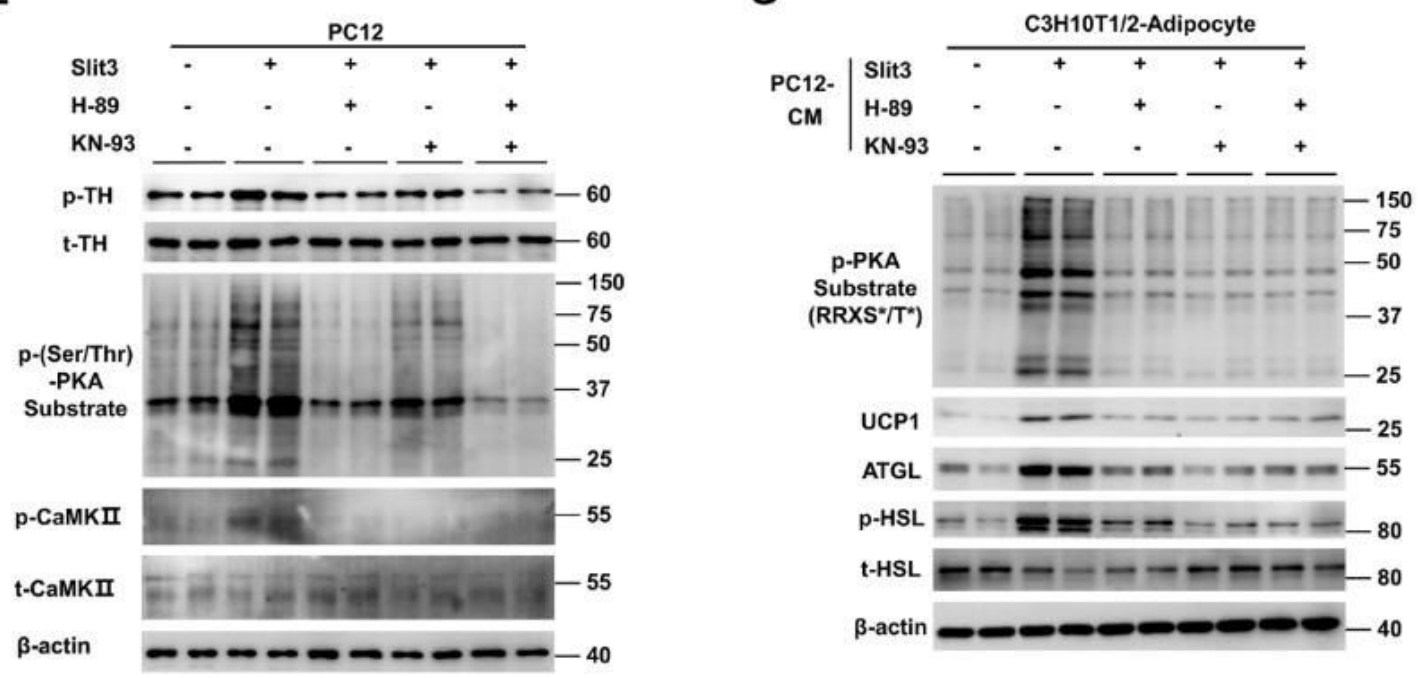

$\mathbf{F}$

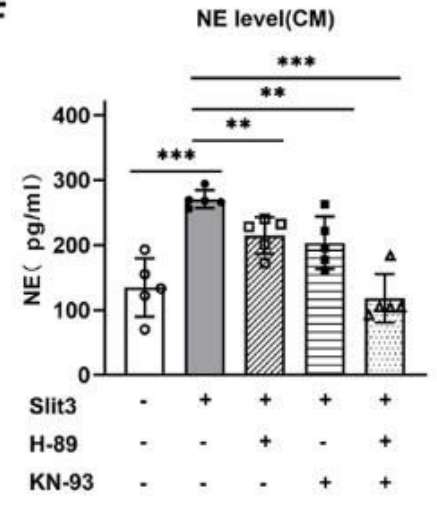

\section{Figure 6}

Slit3 stimulates the phosphorylation of TH via PKA/CaMKII in PC12 sympathetic nerve cells A. Experimental approach to evalute the effect of Sli3 treated PC12 sympathetic nerve cells on C3H10T1/2 adipocytes. B. Western blot analysis of phospho and total TH in PC12 cells with PBS (control) or Slit3 $(1 \mu \mathrm{g} / \mathrm{ml})$ treatment for $24 \mathrm{~h}$. C. Western blot analysis of $\mathrm{p}-(\mathrm{Ser} / \mathrm{PKA}$ substrate, phospho and total CaMKII, phospho and total Erk in PC12 cells with PBS (control) or Slit3 $(1 \mu \mathrm{g} / \mathrm{ml})$ treatment for $24 \mathrm{~h}$. D. Western 
blot analysis of p-(Ser/ PKA substrate, UCP1, ATGL, phospho and total HSL in C3H10T1/2 adipocytes upon $24 \mathrm{~h}$ treatment with conditioned medium from PC12 cells in panel C. E. Slit3 stimulated phosphorylation of TH was suppressed by inhibiting CaMKII with treatment of $10 \mu \mathrm{M} \mathrm{KN} 93$ or inhibiting PKA with treatment of $10 \mu \mathrm{M} \mathrm{H} 89$ in PC12 cells. F. NE levels in PC12 CM with treatment as directed for 24 hours ( $n=5$ per group). G. Western blot analysis for $p$ PKA substrate (RRXS*/T*), UCP1, ATGL, phospho and total HSL in C3H10T1/2 adipocytes upon 24h treatment with conditioned medium from PC12 cells in panel E. Data are presented as mean \pm SEM. Student's $t$ test was used for comparisons. * $p$ $<0.05,{ }^{* \star} p<0.01, * \star * p<0.001, * \star \star \star p<0.0001$.
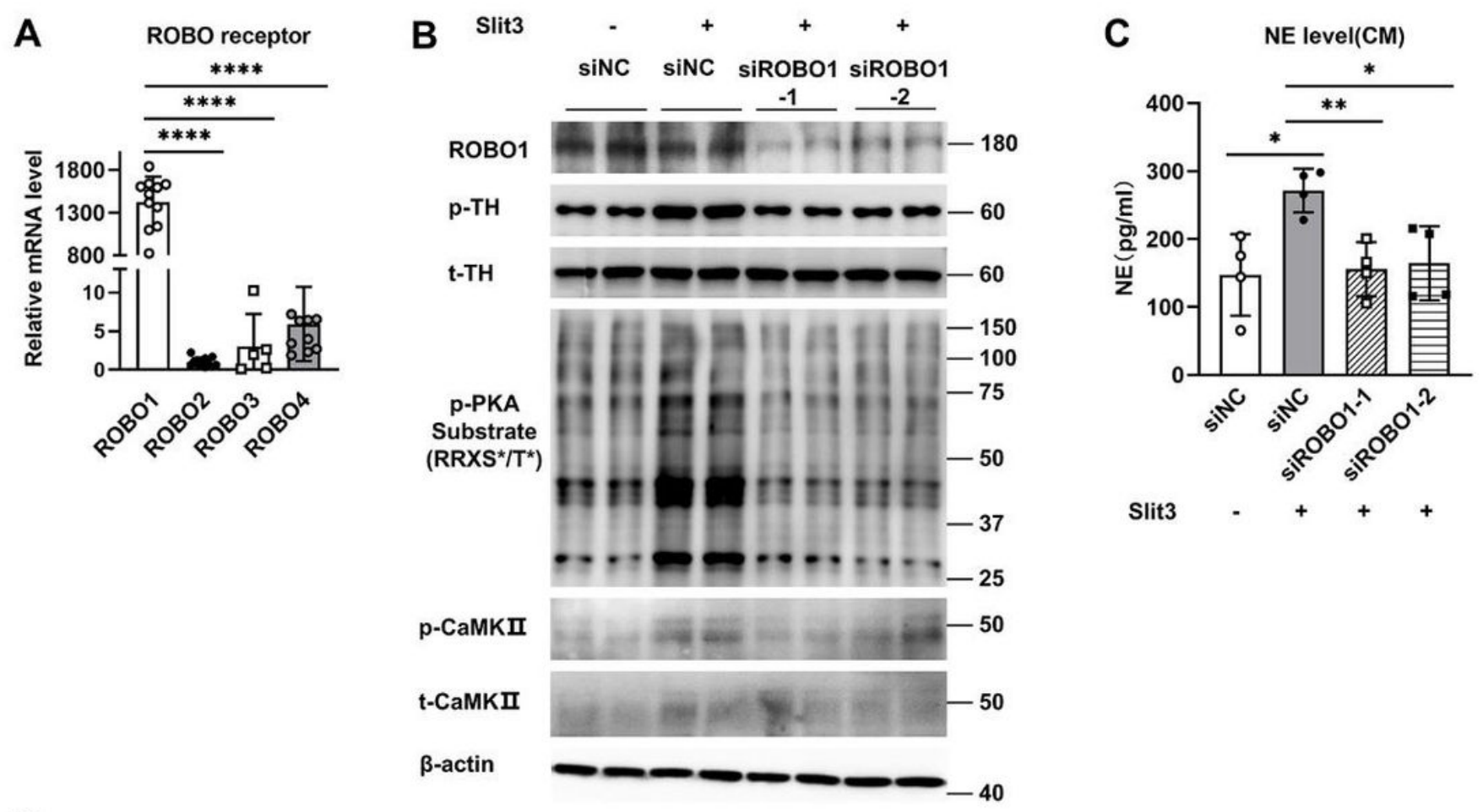

D

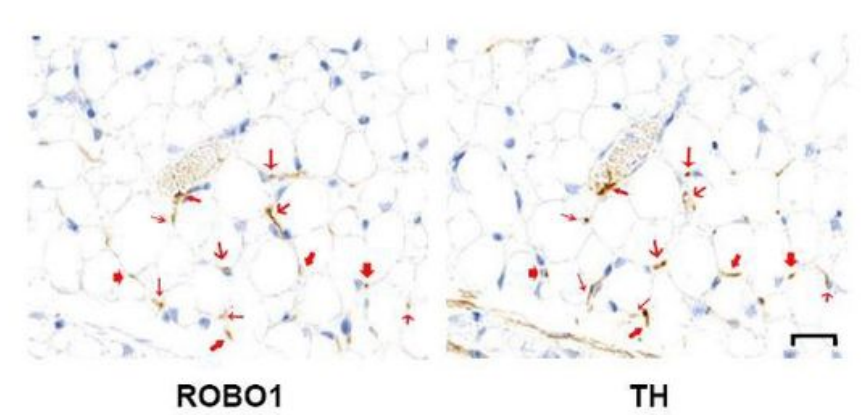

Figure 7

ROBO1 is the receptor for Slit3 to stimulates the phosphorylation of TH and NE production A. Gene expression of ROBO1, ROBO2, ROBO3 and ROBO4 in PC12 sympathetic nerve cells ( $\mathrm{n}=511$ per group). $\mathrm{B}$. Western blot analysis for ROB01, phospho and total TH, p PKA substrate (RRXS*/T*), phospho and total CaMK囚 in PC12 cells upon treatment of siNC or siROBO1, with or without Slit3 for $24 \mathrm{~h}$. C. NE levels in $\mathrm{PC1} 2 \mathrm{CM}$ upon treatment of siNC or siROB01, with or without Slit3 for $24 \mathrm{~h}(\mathrm{n}=4$ per group). D. Staining 
for ROB01 and TH by immunochemistry on sequential sections. Arrows with the same shape indicate the same site. Scale bar: $20 \mu \mathrm{m}$. Data are presented as mean \pm SEM. Student's t test was used for comparisons. * $p<0.05$, ** $p<0.01$, *** $p<0.001$, *** $p<0.0001$.

A

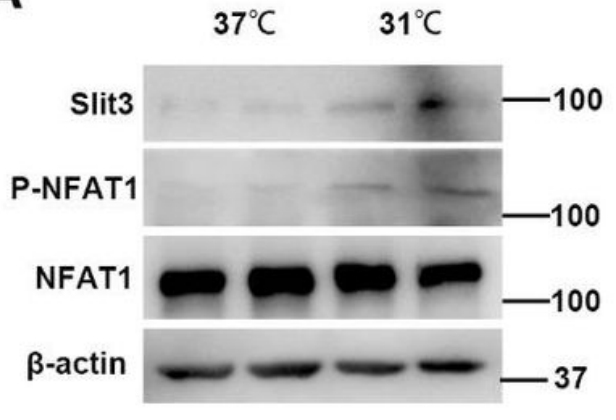

C

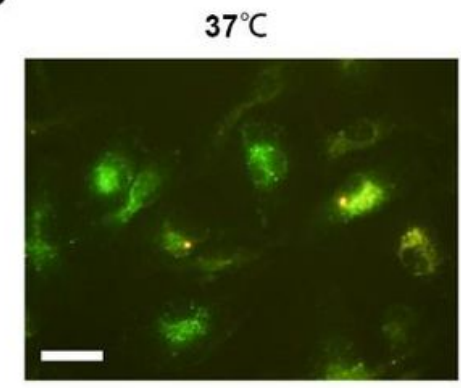

B

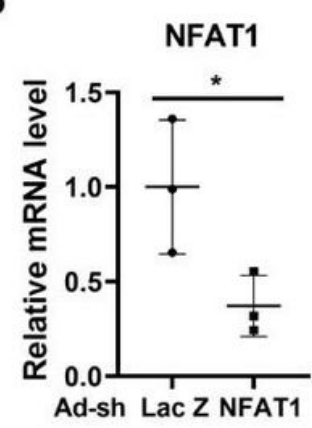

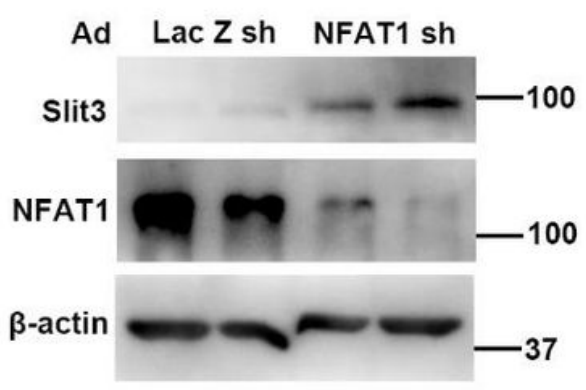

D

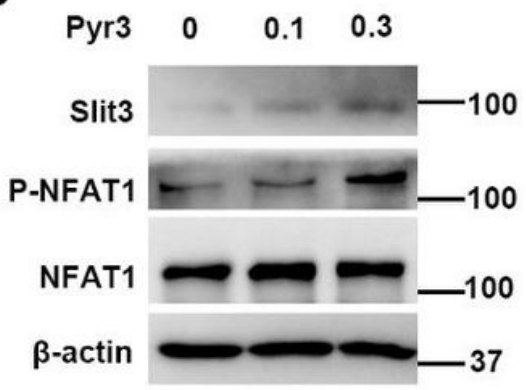

Figure 8

NFAT1 negatively regulate Slit3 expression in M2 macrophage. A: Western blot determine the levels of Slit3, phosphorylated Slit3 (P Slit3) and Slits in BMDM M2 macrophages after incubating at 31区. B: NFAT1 were knockdown by adenovirus carried shRNA, and levels of NFAT1 and Slit3 were determined by qPCR and western blot. Data were collected from 3 individual experiments and analyzed by student's $t$ test. ${ }^{*} p<0.05$. C: BMDM M2 macrophages were at $37 \rrbracket$ or $31 \otimes$ for 60 minutes followed by staining with $4 \mu \mathrm{M}$ calcium indicator Fluo 3 AM for 60 minutes. Images were taken with microscopy. D: BMDM M2 were treated with Pyr3 at concentrations of 0.1 or $0.3 \mu \mathrm{M}$ for 60 minutes, and levels of Slit3, P NFAT1, and NFAT1 were determined. 


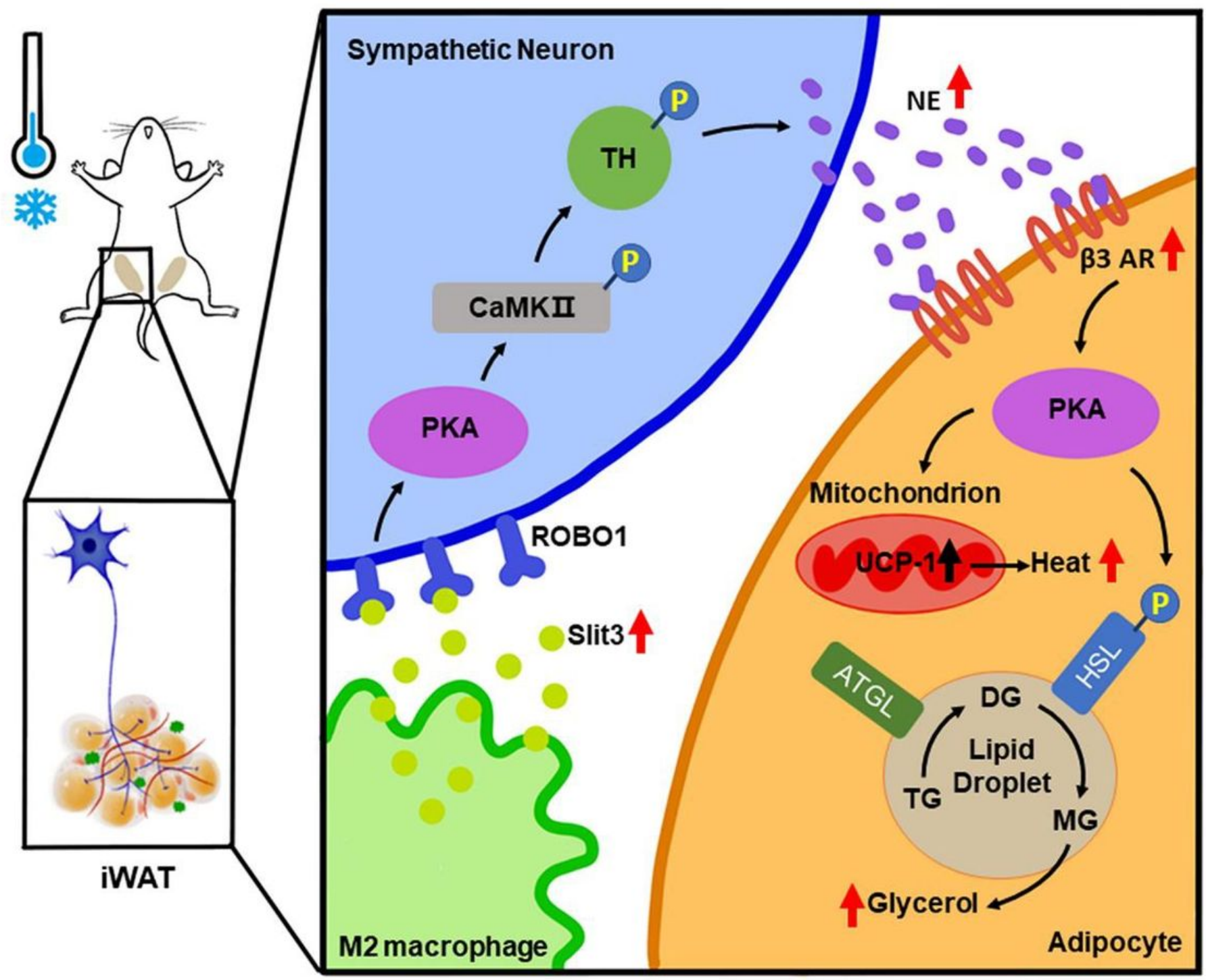

Figure 9

Schematic model for the functions of Slit3 in adipose tissue. When encountered with cold, percentage of M2 macrophages in iWAT was increased and more Slit3 was secreted. Slit3 activated the PKA signaling pathway in sympathetic neurons through the ROBO1 receptor, and promoted the synthesis and release of NE through the phosphorylation of TH via PKA/CaMKII pathway. NE subsequently activated the PKA signaling pathway in adipocytes through $\beta 3$ adrenergic receptor. In adipocytes, activated PKA enhanced lipolysis and glycerol release through phosphorylation of HSL while promoted the expression of UCP1 for uncoupling respiration, so as to maintain the adaptive thermogenesis under cold environment.

\section{Supplementary Files}


This is a list of supplementary files associated with this preprint. Click to download.

- SupplementaryFigures32.pdf 